\title{
EFECTOS DEL MOMENTO DE ASIGNACIÓN DIARIA DE LA PASTURA Y DEL AYUNO SOBRE EL COMPORTAMIENTO INGESTIVO Y LA PRODUCTIVIDAD DE VAQUILLONAS DE BIOTIPO CARNICERO
}

\begin{abstract}
Trabajo presentado como requisito para la obtención del grado académico de MAGISTER SCIENTIAE
\end{abstract}

\section{TESIS}

Del Ingeniero Agrónomo

MARIANO ANTONIO EIRIN

Director: Ing. Agr. M.Sc. Roberto Refi

Codirector: Ing. Agr. Ph.D. Pablo Gregorini

\author{
Maestría personalizada \\ Área Producción Animal
}

Facultad de Ciencias Agrarias y Forestales

Universidad Nacional de La Plata 
Maestría personalizada - Área Producción Animal

Facultad de Ciencias Agrarias y Forestales Universidad Nacional de La Plata

Trabajo presentado como requisito para la obtención del grado académico de MAGISTER SCIENTIAE

EFECTOS DEL MOMENTO DE ASIGNACIÓN DIARIA DE LA PASTURA Y DEL AYUNO SOBRE EL COMPORTAMIENTO INGESTIVO Y LA PRODUCTIVIDAD DE VAQUILLONAS DE BIOTIPO CARNICERO

Tesis del Ingeniero Agrónomo

MARIANO ANTONIO EIRIN 


\section{Agradecimientos}

A Pablo Gregorini por brindarme conocimientos, consejos y su amistad manifestada en su predisposición durante todo el desarrollo de este trabajo.

A Roberto Refi que me brindó mucho más que aportes y sugerencias.

A Charlie, Gastón, Kun, Chapu y todos los alumnos que con su entusiasmo acompañaron este proyecto y con los que a través de estos años conformamos un magnífico grupo de trabajo.

A Javier y familia por su ayuda permanente durante la etapa experimental de campo

A Gilda, Sofi, Manu y mi vieja... 


\section{ÍNDICE}

\section{Página}

Agradecimientos 3

Îndice 4

Índice de Figuras $\quad 5$

Índice de Tablas 6

$\begin{array}{lc}\text { Índice de Fotos } & 6\end{array}$

$\begin{array}{ll}\text { RESUMEN } & 7\end{array}$

1. INTRODUCCIÓN 9

1.1. Hipótesis 11

1.2. Objetivo 11

2. ANTECEDENTES 12

2.1. Variación del valor nutritivo del forraje 12

2.1.1. Factores relacionados al crecimiento de las plantas 12

2.1.2. Variación estacional en la concentración de carbohidratos solubles 15

a) Variación entre ciclos de crecimiento 15

b) Variación dentro del ciclo de crecimiento 17

2.1.3. Variación diaria en la concentración de materia seca y carbohidratos
Solubles.

2.2. Consumo y producción secundaria 21

2.3. Comportamiento del animal en pastoreo 22

2.3.1. Patrón diario de pastoreo 22

2.3.2. Tiempo dedicado a la actividad de pastoreo 24

2.3.3 Momento de asignación diaria de la pastura.

2.3.4. Efecto del ayuno 29

3. MATERIALES Y MÉTODOS 31

3.1. Descripción del área de estudio 31

3.2. Desarrollo experimental 33

3.2.1. Experimento 1 33

a) Generación y caracterización del recurso utilizado

b) Mediciones de calidad del forraje

c) Mediciones de performance productiva

d) Mediciones de comportamiento ingestivo 38

e) Análisis estadístico 40

3.2.2. Experimento $2 \quad 41$

a) Caracterización del recurso utilizado 42

b) Mediciones de calidad del forraje 42

c) Mediciones de performance productiva 42

d) Mediciones de comportamiento ingestivo 44

e) Análisis estadístico 45 
4.1. Experimento $1 \quad 46$

Calidad del forraje $\quad 46$

Consumo y performance productiva $\quad 49$

Comportamiento ingestivo 52

4.2. Experimento $2 \quad 59$

Calidad del forraje $\quad 59$

Consumo y performance productiva 60

Comportamiento ingestivo 62

5. DISCUSIÓN GENERAL 67

6. CONCLUSIONES 72

$\begin{array}{ll}\text { 7. BIBLIOGRAFÍA } & 73\end{array}$

\section{ÍNDICE DE FIGURAS}

Página

Figura 1: Patrón diario de pastoreo de vacas lecheras. 23

Figura 2: Componentes del comportamiento ingestivo. 25

Figura 3: Aumento diario de peso vivo de vaquillonas para carne, en pastoreo rotativo en franjas diarias, durante el invierno, con asignación de forraje matutina (AFM, 7:00 h) o vespertina (AFV, 15:00 h).

Figura 4: Aumento diario de peso vivo de vaquillonas para carne, en pastoreo rotativo en franjas diarias, durante el primavera, con asignación de forraje matutina (AFM, 7:00 h) o vespertina (AFV, 15:00 h).

Figura 5: Patrón de pastoreo de vaquillonas para carne pastoreando franjas diarias en invierno, con asignación de forraje vespertina (AFV; 15:00 h) o matutina (AFM; 07:00 h.)

Figura 6: Patrón de pastoreo de vaquillonas para carne pastoreando franjas diarias en primavera, con asignación de forraje vespertina (AFV; 15:00 hs) o matutina (AFM; 07:00 hs)

Figura 7: Frecuencia y distribución de los eventos de pastoreo, rumia y descanso de vaquillonas para carne bajo un pastoreo en franjas diarias, con asignación vespertina con ayuno (AY) o sin ayuno (SINAY) matutino de 9 hs 


\section{ÍNDICE DE TABLAS}

Tabla 1: Variación de la composición química (\% de MS) durante la horas del día del forraje de una promoción de raigrás, consumido por vaquillonas en un pastoreo intermitente en franjas diarias.

Tabla 2: Tiempos de pastoreo, rumia y descanso (minutos), y tasa de bocado (bocados/ min en cada momento del día) de vaquillonas para carne pastoreando franjas diarias en invierno con asignación de forraje vespertina (AFV) y matutina (AFM).

Tabla 3: Tiempos de pastoreo, rumia y descanso (minutos), y tasa de bocado (bocados/ min) en cada momento del día) de vaquillonas para carne pastoreando franjas diarias en primavera con asignación de forraje vespertina (AFV) y matutina (AFM).

Tabla 4: Variación de la composición química (\% de MS) durante la horas del día del forraje de una promoción de raigrás, consumido por vaquillonas en un pastoreo intermitente en franjas diarias.

Tabla 5: Tiempo total diario de pastoreo, rumia y descanso de vaquillonas para carne, conducidas en franjas diarias con asignación vespertina con (AY) o sin ayuno (SINAY) matutino de 9 hs.

Tabla 6: Tasa de bocado, tiempo de pastoreo, rumia y descanso durante el evento de pastoreo de la tarde de vaquillonas para carne, conducidas en franjas diarias con asignación vespertina con (AY) o sin ayuno (SINAY) matutino de 9 hs.

\section{ÍNDICE DE FOTOS}

Foto 1: Promoción de raigrás anual (Lolium multiflorum Lam.), utilizada como base forrajera del ensayo.

Foto 2: Terneras Aberdeen Angus utilizadas en el ensayo. 


\section{RESUMEN}

El pastoreo es un proceso donde interactúan comportamientos ingestivos $y$ digestivos. Las estrategias de pastoreo responden a dicha interacción, el estado interno del animal y la variabilidad de la composición química de la pastura. En el plazo de 24 hs parte de esta variación de la pastura se debe a importantes fluctuaciones en la fotosíntesis y la transpiración. Ambos procesos incrementarían el valor alimenticio del forraje en horas de la tarde. Varios trabajos evidencian una coincidencia entre dicha variación y el patrón diario de pastoreo de rumiantes. Sin embargo, en animales para carne en crecimiento, pastoreando raigrás anual, tal relación no ha sido detalladamente estudiada antes de este trabajo. Dos experimentos fueron conducidos, uno durante el invierno y la primavera de 2004, y el restante durante las mismas estaciones en 2005, examinando comportamiento y productividad de vaquillonas de biotipo carnicero. En el primer año se realizaron dos tratamientos: Asignación diaria del forraje a la 7:00 hs, (AFM) o a las 15:00 hs (AFV). Las mediciones de comportamiento fueron tiempo de pastoreo (TP), rumia (TR), descanso (TD) y tasa de bocado (TB) durante las horas diurnas. Las mediciones de productividad fueron, aumento diario de peso vivo (ADPV) y cambios en la nota de condición corporal (NCC). Además se estimó el consumo de materia seca (CMS). En el estudio del comportamiento, 4 vaquillonas por tratamiento pastorearon una promoción de raigrás (Lollium multiflorum Lam.) en franjas diarias. En el estudio de la productividad, 48 vaquillonas en las mismas condiciones de pastoreo fueron conducidas en dos grupos de acuerdo a los tratamientos. El tratamiento AFV incrementó el tiempo de descanso $(P<0.01)$ y disminuyó el tiempo de pastoreo $(P<$ 0.01). El AFV concentró el tiempo de pastoreo al atardecer, cuando laTB fue máxima $(P<0.01)$. El tiempo de rumia varió de acuerdo al momento del día $(P<0.01)$, pero el tiempo total de rumia no difirió. $(P=0.11)$. En AFV el tiempo de rumia y descanso se concentró en la mañana y el mediodía. En cuanto a la productividad, durante el invierno hubo efecto tratamiento $x$ semana $(P<0.01)$ para ADPV y NCC: a partir de la semana 4 los animales en AFV aumentaron $150 \mathrm{~g}$ de $P V$ y 0.0145 puntos de NCC más por día que en el tratamiento AFM $(P<0.05)$. En primavera ese incremento fue 540 grs. y 0.0145 puntos $(P<0.05)$ más por día durante todo el periodo. El CMS (kg $x$ animal /día) no difirió ( $P>0.05$ ) en invierno (AFM 4.5 vs. AFV 5) ni en primavera (AFM 5 vs. AFV 5.6).

Durante el segundo año se evaluó el efecto de ayuno matutino. Los tratamientos fueron: asignación diaria del forraje vespertina con ayuno matutino (AY), y sin ayuno (SINAY). Estudios de comportamiento y productividad fueron conducidos simultáneamente. Los primeros en la forma descripta para el primer año $y$ en los segundos 58 vaquillonas fueron distribuidas al azar en dos grupos de acuerdo a los tratamientos. Los animales fueron pesados, evaluada la NCC y estimado el CMS cada 14 días. El ayuno tendió a incrementar (en 20 min.) el pastoreo vespertino $(P=0.10)$, y redujo $(P<0.09)$ el tiempo de descanso (16 min.). La rumia fue de 0 min. para ambos tratamientos. La tasa de bocado se incrementó $(P<0.01)$ en AY comparada con SINAY (62 vs. 54 bocados/min.). Los tratamientos no afectaron el ADPV (0.66 kg animal /día; $P=0.88)$, los cambios en NCC (0.0135; $P=0.77)$, ni el CMS (4.43; $P=0.19)$. 
Estos resultados sugieren que el momento de asignación diaria del forraje y los ayunos matutinos alteran los patrones de pastoreo, rumia y descanso. La asignación vespertina conduce a eventos de pastoreo más largos e intensos cuando el forraje tiene mejor calidad, lo que incrementa la producción secundaria. El Ayuno matutino generó igual producción secundaria en sesiones de pastoreo más cortas.

Palabras claves: patrón de pastoreo, comportamiento ingestivo, composición química del forraje, ganancia de peso, condición corporal, vaquillonas para carne. 


\section{INTRODUCCIÓN}

El pastoreo es un proceso dinámico y continuo donde comportamientos ingestivos y digestivos interactúan en espacio y tiempo (Gregorini et al., 2006). E resultado de cualquier estrategia de pastoreo, ya sea del comportamiento natural del animal o impuesto por el productor, resulta no sólo de dicha interacción sino también de la variabilidad de la composición química y la estructura del forraje en pie (Mattiauda, 2003). Por lo tanto, un mejor entendimiento y manejo del proceso de pastoreo y su patrón, ayudaría a los productores a asignar con mayor eficiencia los nutrientes provenientes de las pasturas

La variabilidad en la composición química de las pasturas se halla a diferentes escalas espacio-temporales. Es decir, la variación se produce tanto a nivel de comunidades de plantas como en partes de la planta, en períodos que van desde pocos segundos hasta estaciones (Delagarde et al., 2000). Esto sobrelleva no solo importantes fluctuaciones en la composición química, sino también en la disponibilidad y accesibilidad de forraje, y por ende en los nutrientes aportados por el mismo. En el lapso de un día, la composición química del forraje varía debido a la fluctuación natural diaria en la fotosíntesis, transpiración y otros procesos fisiológicos (Mayland et al., 2005). Varios estudios en Gran Bretaña (Waite \& Boyd 1953 y Orr et al., 1997; 2001), en Nueva Zelandia (Kingsbury 1965), en Australia (Fulkerson et al., 1994), en USA (Fisher et al., 1998 Gregorini et al., 2008; 2009a) y en Francia (Delagarde et al., 2000) han demostrado que las concentraciones de materia seca (MS) y carbohidratos no estructurales (CNES) del forraje, aumentan en el transcurso del día. Esta variación ocurre principalmente en los horizontes superiores del canopeo (Delagarde et al., 2000), generando incrementos en la digestibilidad de la 
MS (Linnane et al., 2001), en la palatabilidad (Provenza et al., 1998) y una reducción en la fuerza a ejercer por el animal durante las masticaciones de consumo y rumia (mayor facilidad de reducción de tamaño de partícula) (Gregorini et al., 2009a). Consecuentemente, dicha variación incrementaría el valor nutritivo y alimenticio del forraje pastoreado en horas de la tarde.

Independientemente de la forma en que el forraje es ofrecido, los rumiantes consumen en un número discreto de comidas, sesiones de pastoreo (SP) (Gregorini et al.; 2006). Las SP se alternan con períodos de rumia y descanso (ausencia de actividad de ingestión o rumia) (Forbes, 1995). La opción de qué actividad desarrollar dependería del ambiente y del estado interno o fisiológico pasado y actual del animal, como también de las expectativas de estados futuros (Mangel \& Clark, 1986). El estado interno dependería de tres variables (Newman et al., 1995): la cantidad de energía reservada (para crecimiento, mantenimiento y reproducción), la cantidad de material digestible en el tracto gastrointestinal (TGI) del animal y la cantidad de material no digestible en el mismo sitio. Es así que la interacción con el medio ambiente y el manejo del estado interno del animal pueden variar la cantidad e intensidad de SP (por ej., generar mayor duración y mayor tasa de bocado, por lo tanto mayor consumo) (Patterson et al., 1998).

Los resultados observados en rumiantes salvajes como el Búfalo africano (Sinclair, 1977) y el Bisonte (Hudson \& Frank, 1987) y en domésticos tales como ovejas (Penning, 1991a, Champion et al., 1994; Orr et al., 1997) y vacas lecheras (Gibb et al., 1998; Barret et al., 2001; Orr et al., 2001) pastoreando pasturas templadas, indican una correspondencia entre el aumento del valor nutritivo y alimenticio del forraje en horas de la tarde y el patrón diario de pastoreo (Gregorini et 
al., 2006). Esto evidenciaría la capacidad de los rumiantes de detectar y utilizar la variabilidad diaria natural de las plantas y maximizar su cosecha de energía.

El conocimiento de la variabilidad diaria en la composición química de la planta y del comportamiento ingestivo del animal nos permite determinar el aporte de nutrientes de las pasturas, su posible manipulación (Beever \& Siddons, 1986 y Chilibroste et al., 2005) y el impacto en la producción secundaria. El presente trabajo intenta realizar un aporte a la base científica local, para asegurar un desarrollo tecnológico más eficaz, basado en medidas de manejo del pastoreo que aumenten la eficiencia de utilización de los nutrientes ofrecidos por la pastura.

\subsection{Hipótesis}

El momento de asignación diaria de la pastura y ayunos estratégicos altera el patrón diario de pastoreo y afecta la productividad de vaquillonas de biotipo carnicero en crecimiento.

\subsection{Objetivo}

El objetivo de este trabajo fue estudiar la influencia del momento de asignación de la pastura y de ayuno previo a la asignación vespertina de la pastura sobre la distribución diurna del tiempo de pastoreo, rumia, y descanso, tasa de bocado, ganancia diaria de peso vivo y cambios en nota de condición corporal de vaquillonas de biotipo carnicero en crecimiento. 


\section{ANTECEDENTES}

\subsection{Variación del valor nutritivo del forraje}

Se consideran como "pasturas de calidad" a aquellas de las cuales se obtiene la mejor respuesta animal. El valor nutritivo puede ser definido como la respuesta animal por unidad de consumo de alimento, y está conformado por tres factores: la composición química; la proporción que es digerida o digestibilidad aparente y la eficiencia con que los nutrientes digeridos son utilizados para mantenimiento y producción (Ulyatt, 1973).

\subsubsection{Factores relacionados al crecimiento de las plantas}

Si bien la fotosíntesis ocurre exclusivamente en las horas diurnas, la respiración y traslocación de los fotosintatos se desarrollan durante las 24 horas del día. Durante las horas de luz los hidratos de carbono sintetizados por la planta superan a los utilizados en el proceso de respiración, y el excedente es traslocado a los órganos de reserva de la planta como son las vainas, raíces, etc.

Para comprender mejor estos cambios es necesario describir como ocurre el crecimiento de la planta en forma individual, y de la pastura en su conjunto. Este sigue generalmente una curva sigmoidea desde el momento de su establecimiento hasta la muerte en especies anuales, o hasta el estado de equilibrio alcanzado en plantas perennes. El crecimiento luego del pastoreo (rebrote) es primero lineal y luego asintótico. La tasa de crecimiento de una pastura en su fase asintótica de la curva de rebrote depende de la intercepción de la radiación y las diferencias 
genéticas en la respuesta a la utilización de esa radiación; del balance de carbono; del medio ambiente y del manejo (Pearson \& Ison, 1994).

a) Intercepción de la radiación: La radiación disponible para el crecimiento de las pasturas cambia con un patrón estacional de acuerdo con la latitud y es atenuada a medida que atraviesa las capas de la atmósfera, nubes y las partículas sólidas. Aproximadamente el $50 \%$ de la radiación neta corresponde a la radiación fotosinteticamente activa (RFA) (Pearson \& Ison, 1994). La eficiencia fotosintética potencial de la hoja es de alrededor de $12 \mathrm{~g}$ de $\mathrm{CO}_{2}$ por $\mathrm{MJ}$ de radiación (CharlesEdwards, 1982). El costo energético varía de acuerdo con los componentes que se producen: carbohidratos, proteínas y lípidos. Estos tienen valores energéticos de 17, 24 y $37 \mathrm{KJ}$ por gramo, respectivamente. De este modo, si las pasturas tuviesen sólo hidratos de carbono, la eficiencia fotosintética debería ser de $8 \mathrm{~g}$ MS por MJ, pero si además contuviesen $12 \%$ de proteína y 3\% de lípidos sería, entonces, de 7,4 g MS por MJ para el caso de las gramíneas. Existe por ello un conflicto entre la complejidad química del forraje (y por ende su valor nutritivo) y la productividad de materia seca.

b) Balance de carbono: La tasa de crecimiento de la planta entera o de una pastura, no está relacionada simplemente con su tasa de fotosíntesis. Esto es debido a que a nivel de la pastura, el crecimiento está principalmente determinado por el tiempo transcurrido bajo condiciones favorables para el desarrollo (Monteith \& Elston, 1983). La respiración consume entre 20 y $60 \%$ de la producción diaria de fotosintatos. La pérdida de productividad frente a la eficiencia potencial es generalmente del $50 \%$, pero puede que ocasionalmente sea tan alta como un $80 \%$ en condiciones de campo, donde es difícil discriminar las pérdidas entre el gasto 
por la respiración y la pérdidas por muerte de tejido. A su vez, la senescencia es el principal causante de la pérdida de valor nutritivo.

c) Medio ambiente: Participa en el crecimiento de las plantas con dos tipos de factores: Aquellos que no suministran elementos que componen la planta, como la temperatura, que actúa principalmente sobre la velocidad de los procesos bioquímicos, determinando, a su vez, el hecho de que sea o no capaz de crecer (letargos de los granos, reposos estacionales); y factores que suministran los elementos que constituyen las plantas, como el agua y los nutrientes. La primera fisiológicamente esencial como alimento y medio interno y para el mantenimiento de la turgencia, expansión celular y crecimiento. Y los nutrientes, que suministran a la planta los átomos con los que está formada la materia orgánica $(\mathrm{C}, \mathrm{N}, \mathrm{H}$ y O) y definen su valor nutritivo.

d) Manejo (Senescencia y acumulación neta de forraje): En los estadios tempranos de rebrote la muerte de hojas, y por consiguiente la pérdida de valor nutritivo, es escasa o nula, y la acumulación neta de forraje iguala a la tasa de asimilación neta del canopeo. Las primeras hojas en morir durante el rebrote son aquellas producidas al comienzo del período; estas hojas son más pequeñas que las que se producen subsecuentemente, de modo que la tasa de muerte, en términos de flujo de masa, inicialmente se retrasa en relación a la tasa de producción de nuevos tejidos (Robson et al., 1989). La tasa de acumulación neta de forraje es máxima durante este período de retraso, pero posteriormente decrece hasta que la tasa de muerte de tejidos iguala a la tasa de producción de nuevos tejidos y el techo de producción de tejido vivo es alcanzado. A partir de este momento el valor nutritivo se estabiliza, o decrece si la pastura pasa al estado reproductivo o se acumula excesivo material muerto. 


\subsubsection{Variación estacional en la concentración de carbohidratos solubles}

\section{a) Variación entre ciclos de crecimiento}

Los factores que determinan el contenido de Nitrógeno ( $\mathrm{N}$ - utilizado para la producción de proteína microbiana y animal), Carbohidratos No Estructurales (CNES - energía rápidamente disponible para los microbios del rumen) y Materia Seca (MS - carácter relacionado con la energía total disponible) en el forraje (biomasa acumulada, tasa de crecimiento, fotosíntesis, morfología de la planta, etc.), pueden variar dentro del mismo ciclo de crecimiento y también de un ciclo a otro, como consecuencia de las condiciones ambientales y de manejo que se presenten.

Por ejemplo, durante el crecimiento y desarrollo de los verdeos de invierno se suceden varios ciclos de crecimiento que suelen corresponderse con los ciclos de aprovechamiento por parte de los animales. Cada uno de estos ciclos ocurre en un momento del año diferente, en estaciones climáticas diferentes, con características ambientales propias de la estación, de la región o del año en cuestión. Por ello cuando se evalúa el efecto del ciclo de crecimiento (inicial, primer o segundo rebrote) sobre la composición química del forraje, generalmente se incluye un efecto asociado a condiciones ambientales propias del momento durante el cual transcurre cada ciclo de crecimiento (White, 1973)

El contenido de CNES, de MS y la biomasa acumulada son generalmente menores, y el nivel de proteína bruta (PB) mayor, en el forraje de otoño respecto del de primavera (Reeves et al., 1996; Delagarde et al., 2000). Radojevic et al. (1994) realizaron una experiencia en región templada, donde las condiciones del invierno no son propicias para la acumulación de carbohidratos solubles. Las 
mayores concentraciones se presentaron a fines del verano, cuando la radiación solar fue elevada. Sin embargo en regiones templadas de Nueva Zelandia e Inglaterra los niveles de carbohidratos solubles son máximos durante el invierno, a pesar de la densa nubosidad (Fulkerson et al., 1998). Esto nos está indicando que las menores pérdidas por respiración durante la estación fría en dichas regiones, prevalecen sobre la disminución de la fotosíntesis debida a la alta nubosidad.

Gran parte de la información bibliográfica coincide en que el nivel de CNES en primavera es mayor que en el otoño (Elizalde et al., 1994; Boudon \& Peyraud, 2001), a pesar de que la tasa de crecimiento en primavera y por lo tanto la demanda de carbohidratos solubles, también es superior. Esto podría deberse a que conjuntamente con una elevada tasa de crecimiento, se incrementa el área foliar, y con ello la radiación interceptada y la actividad fotosintética de la pastura (Wulfes et al., 1999). La mayor temperatura y radiación durante la mañana en la primavera podrían favorecer directamente la tasa de fotosíntesis y, a su vez, las temperaturas frescas durante la noche reducirían las pérdidas de carbohidratos solubles por respiración. Garza et al. (1965) encontraron que el nivel de carbohidratos solubles en alfalfa fue mayor cuando las plantas crecían bajo un régimen de temperatura de $30^{\circ} \mathrm{C}$ durante el día y de $15^{\circ} \mathrm{C}$ durante la noche, en comparación al crecimiento a una temperatura constante de $30^{\circ} \mathrm{C}$. A su vez, estas últimas presentaban un nivel de carbohidratos mayor que las plantas que crecían a una temperatura constante de $15^{\circ} \mathrm{C}$. Si bien la relación hoja/tallo en estas tres situaciones fue diferente, lo cual explicaría en parte las diferencias en cuanto al nivel de carbohidratos, el incremento de temperatura diurna y las bajas temperaturas nocturnas podrían favorecer la acumulación de carbohidratos solubles. 


\section{b) Variación dentro del ciclo de crecimiento}

La composición química del forraje es variable no solo entre estaciones o ciclos de crecimiento sino también dentro del mismo ciclo de crecimiento (White, 1973). La edad del rebrote es un factor que tiene influencia sobre la composición química del forraje. A medida que transcurren los días y la biomasa acumulada aumenta, la proporción de lámina disminuye, el nivel de MS y CNES aumenta y se reduce el contenido de $\mathrm{N}$ en la planta (Wilman, 1965; Reeves et al., 1996).

Las variaciones en la composición química durante un ciclo de crecimiento dependen de la estación del año en que transcurre dicho ciclo. Delagarde et al. (2000) observaron que los cambios en el contenido de CNES y PB en raigrás perenne fueron de mayor magnitud durante el ciclo de primavera que durante el ciclo de otoño. Fulkerson et al. (1998) encontraron que durante la primavera tardía no hubo cambios significativos en el contenido de CNES ni de PB, mientras que durante el invierno el nivel de CNES de raigrás perenne se incrementó del 5 al 28\% y el contenido de PB disminuyó del 22 al 15\%.

La información revisada sugiere que los procesos que determinan la concentración de CNES, PB y MS en los forrajes frescos son los mismos entre regiones, entre ciclos de crecimiento y entre momentos dentro del mismo ciclo. La composición química del forraje es dependiente de la región y de la estación del año, en función de las condiciones ambientales y climáticas que caractericen a cada una de ellas. 


\subsubsection{Variación diaria en la concentración de materia seca, carbohidratos solubles y proteínas.}

Las variaciones en el contenido de MS del forraje fresco dependen del contenido de agua interna y externa como lluvia o rocío (Cabrera Estrada et al., 2004). Los procesos metabólicos que ocurren en la planta entre la mañana y el atardecer involucran principalmente una pérdida de agua y una ganancia de fotosintatos (Delagarde et al., 2000). La pérdida de agua durante las horas de luz resulta de una disminución de agua superficial por evaporación y de una pérdida de agua interna debido al balance negativo entre la absorción y la transpiración, que juntamente con la síntesis de carbohidratos determina un incremento en el contenido de MS del forraje (Van Vuuren et al., 1986). La variación en la concentración de MS en el forraje durante el día oscila entre 3.5 y 6 puntos porcentuales dependiendo, entre otros factores, de la estación del año. Delagarde et al. (2000) observaron que tanto la concentración promedio de MS como la diferencia entre la mañana y la tarde fueron mayores en la primavera respecto del otoño $(23,6 \%$ y 4,4 puntos porcentuales y $16,0 \%$ y 1,9 puntos porcentuales en primavera y otoño, respectivamente).

La concentración de CNES en el forraje se incrementa durante las horas de luz y disminuye durante la noche como consecuencia del balance entre la cantidad que se produce por fotosíntesis y la que se consume por respiración (Ciavarela et al., 2000 a,b; Trevaskis et al., 2004). El aumento en el porcentaje de CNES durante el día se debe principalmente a un incremento en el contenido de sucrosa, producto inmediato de la fotosíntesis (Lechtemberg et al., 1971; Sicher \& Kremer, 1984). Lechtenberg et al. (1972) observaron que el 63\% de la sucrosa acumulada durante 
el día en el forraje de festuca (Festuca arundinacea) era consumido por la planta entre las 12 de la noche y las 6 de la mañana.

Según la bibliografía revisada, la magnitud de los cambios en el nivel de CNES durante el día oscila entre 1 y 6 puntos porcentuales. Estos cambios representan aproximadamente entre un 15 y un $70 \%$ de incremento en la concentración de carbohidratos de la planta, dependiendo de la magnitud de dichos cambios y del porcentaje de carbohidratos al inicio del día. Por ejemplo, en la experiencia de Delagarde et al. (2000), el incremento durante el día fue de 2.4 puntos porcentuales lo cual representó un 13\% de aumento, partiendo de $18.5 \%$ de carbohidratos a la mañana. Ciavarela et al. (2000a) observaron un incremento de 5.7 puntos porcentuales sobre un valor mínimo de carbohidratos de $10.3 \%$ (55\% de aumento). Gregorini et al. (2009a) encontraron en festuca incrementos del $46 \%$ entre las 6:50 hs y las 19:25 hs.

La diferencia en el contenido de CNES entre la mañana y la tarde es menor en los estratos inferiores de la pastura que en los superiores, lo cual se debería a una menor proporción de láminas y a la reducción en la fotosíntesis como consecuencia del crecimiento sombreado en los estratos más bajos de la pastura (Delagarde et al., 2000). A su vez, el nivel de CNES a la mañana es superior en el estrato localizado entre $5-10 \mathrm{~cm}$ del suelo y a la tarde en el estrato ubicado por encima de los $15 \mathrm{~cm}$ (más folioso). El resultado que se observa a la mañana es reflejo de lo que ocurre durante la noche; esto es, durante la noche el nivel de CNES disminuye tanto en hojas como tallos, aunque en las hojas los CNES se consumen y/o exportan en una mayor proporción que en los tallos (Lechtenberg et al., 1971). 
La variación en el porcentaje de PB durante el día es de menor magnitud que la variación en la concentración de CNES (Van Vuuren et al., 1986). Delagarde et al. (2000) observaron diferencias significativas de 1.1 unidades porcentuales entre la concentración de PB de la mañana (17.7\%) y la tarde (16.6\%), lo que representa una disminución del 6.2\%. La magnitud de la diferencia entre la mañana y la tarde puede variar en función de la estación del año. Delagarde et al. (2000) observaron un menor porcentaje de PB y una mayor variación durante el día en la primavera respecto del otoño (15.3\% y 2.2 puntos porcentuales versus $23.2 \%$ y 0.4 punto porcentual en primavera y otoño, respectivamente).

Los componentes nitrogenados de las plantas no son productos iniciales de la fotosíntesis ni sustratos inmediatos para la respiración. Por ello el metabolismo del $\mathrm{N}$ está menos influenciado de manera directa por los cambios ambientales diurnos que el metabolismo de los carbohidratos (Youngberg et al., 1972). El porcentaje de proteínas en el forraje puede disminuir durante el día (Youngberg et al., 1972; Delagarde et al., 2000; Trevaskis et al., 2004), o no presentar variaciones significativas (Reeves et al., 1996; Ciavarela et al., 2000a). La disminución en la concentración de PB durante el día se debería a un efecto de dilución dentro de la MS como consecuencia del incremento en la concentración de CNES (Lechtenberg et al., 1971; Youngberg et al., 1972; Delagarde et al., 2000). Youngberg et al. (1972) observaron que la concentración de N en la MS "residual" (materia seca total menos el contenido de carbohidratos solubles) se mantenía relativamente constante durante el día, lo cual indica que las variaciones diurnas de $\mathrm{N}$ en la MS total son consecuencia de las fluctuaciones en el contenido de CNES. 


\subsection{Consumo y producción secundaria}

La producción secundaria de los sistemas ganaderos basados en la utilización de pasturas, depende en gran medida de la cantidad y calidad del forraje producido y la capacidad del animal para cosecharlo y utilizarlo eficientemente. También es función de la capacidad del productor para manejar este proceso de pastoreo; todo lo cual, determina el consumo de materia seca de forraje (Laca \& Greenwood, 1987).

Las teorías convencionales sobre el consumo de forraje de los rumiantes se sustentaron en controles físicos y metabólicos del apetito (Mertens, 1994; Miner \& Baile, 1991; Baile \& Forbes, 1974; Bines, 1971) estrechamente ligados a la digestibilidad del forraje, pero sin tener en cuenta la influencia directa que las características "no nutricionales" de la vegetación (estructura y morfología del canopeo, densidad, altura, etc.) ejercen bajo condiciones de pastoreo (Hodgson, 1982). A partir de una revisión crítica de los trabajos que dieron origen a aquellas teorías, Grovum (1987) sugiere abandonar la idea del consumo regulado por un solo factor, debiéndose considerar la acción conjunta de diversos agentes: físicos, metabólicos, químicos y humorales.

Además del nivel de consumo es necesario considerar la capacidad del forraje para aportar al animal energía y otros nutrientes que pueden ser limitantes (proteínas, minerales y vitaminas). El consumo de nutrientes, a su vez, es el producto de la cantidad de pastura consumida y la concentración de nutrientes de dicho forraje, pudiendo ocurrir que aunque no existan restricciones en la disponibilidad de forraje, un déficit en la composición química disminuya la cantidad de nutrientes cosechada por el animal. 
La producción de carne sobre verdeos invernales ha encontrado limitantes para su máxima expresión, debido a las bajas ganancias de peso registradas durante el primer aprovechamiento o ciclo inicial de crecimiento (Méndez \& Davies, 2003). El forraje de otoño se caracteriza por presentar bajos contenidos de MS y CNES y altos contenidos de PB. Ante esta situación, parte del N consumido no podrá ser captado por las bacterias del rumen, el cual se eliminaría en forma de urea a través de la orina, constituyendo una pérdida de $\mathrm{N}$ y una ineficiencia en el uso del $\mathrm{N}$ para el rumiante. La baja relación CNES/PB y el bajo contenido de MS de los forrajes frescos han sido propuestos como responsables, al menos en parte, de las bajas ganancias de peso en el periodo otoño-invernal (Ribeiro et al., 1981; Elizalde \& Santini, 1992), caracterizando al forraje fresco de otoño como un alimento desbalanceado desde el punto de vista de la producción animal. Esta situación podría atenuarse por la tarde y/o a medida que el ciclo de crecimiento avanza, debido al aumento en la concentración de CNES, y la disminución en el contenido de agua, como se describió en 2.1.3., lo cual conduciría a un aumento en la facilidad de cosecha.

\subsection{Comportamiento del animal en pastoreo}

\subsubsection{Patrón diario de pastoreo}

Independientemente de la forma en que el forraje es ofrecido, los rumiantes en pastoreo consumen su alimento en un número discreto de comidas, denominados sesiones de pastoreo (SP) (Gregorini et al., 2006). Las SP pueden definirse como períodos de tiempo ininterrumpidos en que el animal pastorea sin parar, donde se dedica a la búsqueda, aprehensión y deglución de forraje (Gibb, 1998). Las SP se 
alternan con períodos de rumia y descanso (Forbes, 1995). Los descansos registrados en la actividad de pastoreo mayores a 5 minutos pueden ser considerados como límites a cada una de las SP. Los descansos menores de 5 minutos pueden ser considerados como intervalos intra SP (Rook et al., 1994).

Los vacunos muestran un patrón básico de pastoreo, dado por la frecuencia y distribución de las SP (Hodgson, 1990). Pueden distinguirse tres o eventualmente cuatro SP importantes a lo largo del día, ubicándose las más relevantes a la mañana temprano y al final del día (Figura 1). De igual manera, similares patrones de comportamiento ingestivo han sido descriptos en vaquillonas para carne en crecimiento (Gregorini et al., 2007) y en ovinos (Penning et al., 1991b; Orr et al., 1997).

Horas del día

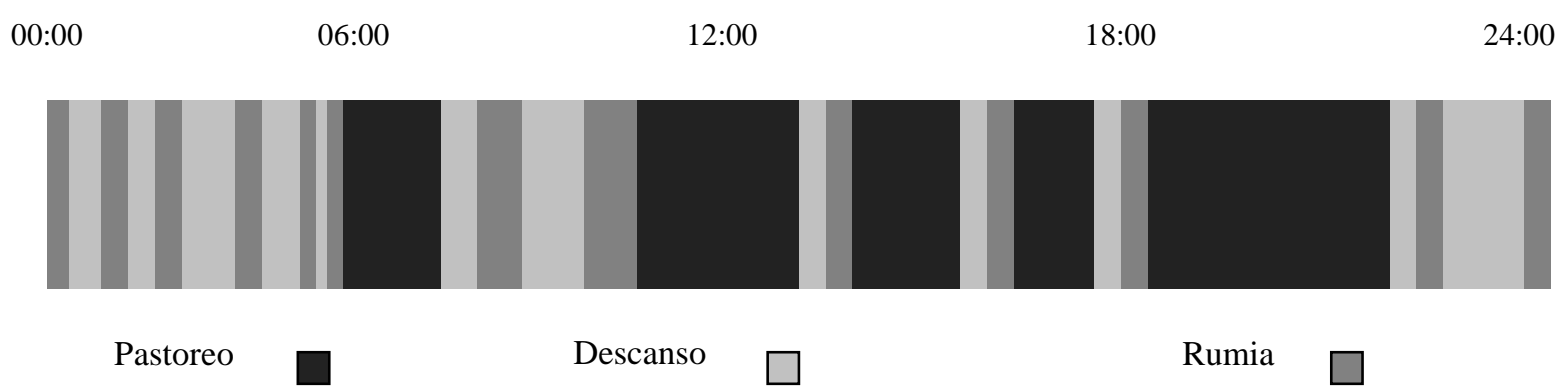

Figura 1: Patrón diario de pastoreo de vacas lecheras. (Adaptado de Gibb et al., 1998)

Según el análisis efectuado por Arnold \& Dudzinsky (1978) el patrón diario de pastoreo, de diferentes rumiantes, es afectado por factores tales como la duración del día, la temperatura y la humedad del ambiente, la lluvia y el viento, la cantidad de alimento disponible, y las diferencias entre individuos. 
Autores como Provenza et al. (1998) sugirieron que el comportamiento en pastoreo puede estar relacionado con los cambios diurnos en la calidad del alimento. De tal manera, los animales preferirían un alimento con alto contenido en macronutrientes y de mayor digestibilidad como el observado en las últimas horas de la tarde (Provenza, 1996). Una intensa SP en dichas horas puede constituir, tanto una respuesta a la mayor densidad energética de la pastura al final del día, maximizando así la relación costo-beneficio de la cosecha de nutrientes (Thornley et al., 1994; Ketelaars \& Tolkamp, 1992), como un intento de los animales de obtener la mayor cantidad de alimento posible antes de que llegue la noche, período en el que bajo condiciones silvestres los rumiantes estarían expuestos a la presencia de predadores (Charnov et al., 1976). Los rumiantes domésticos mantendrían ese comportamiento atávico (Gregorini et al., 2006)

\subsubsection{Tiempo dedicado a la actividad de pastoreo}

La habilidad de un animal en pastoreo para mantener niveles adecuados de consumo depende de su capacidad para modificar su comportamiento ingestivo en respuesta a cambios en la estructura de la pastura (Allden \& Whittaker, 1970). Desde un punto de vista mecanicista, como se ve en la Figura 2, el consumo queda determinado por el producto del peso del bocado, la tasa de bocados y el tiempo de pastoreo. El peso del bocado puede expresarse en términos del volumen de dicho bocado (profundidad x área) y la densidad del forraje en el horizonte de pastoreo y es la variable del comportamiento ingestivo que mayor efecto tiene en el consumo (Chacón \& Stobbs, 1976). 
Figura 2: Componentes del comportamiento ingestivo. (Hodgson, 1982).

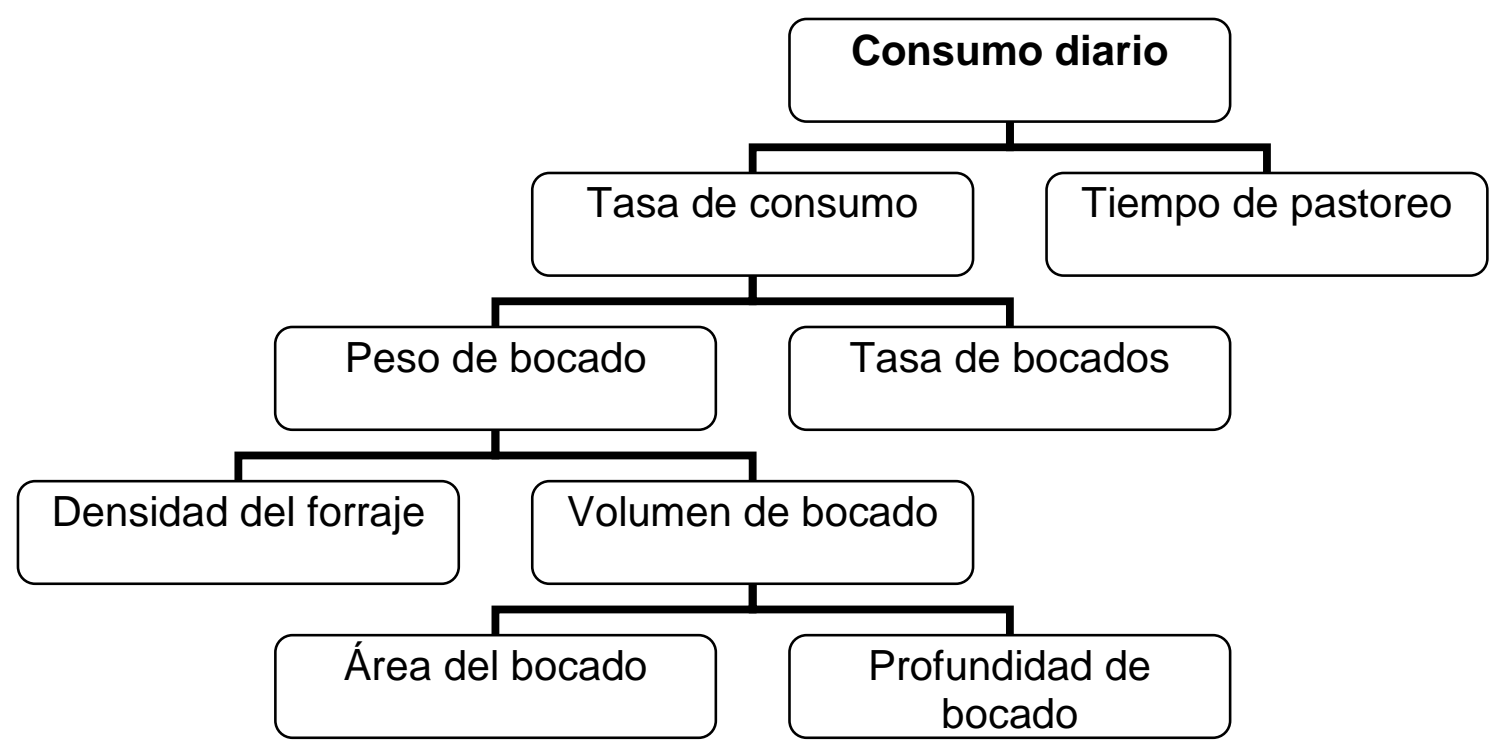

Teniendo en cuenta que la tasa de consumo es calculada como el producto de la tasa de bocado por el peso de bocado (TB x PB), el tiempo de pastoreo puede considerarse una variable dependiente. Luego, a través del tiempo dedicado al pastoreo el animal tendría la capacidad de mantener una determinada tasa de consumo en el caso que las condiciones de la pastura sean limitantes. Esta capacidad del animal para modificar el tiempo de pastoreo se halla en un rango que varía entre 4 y 14 horas diarias para el ganado de carne (Arnold \& Dudzinsky, 1978). Además, estos autores determinaron que el promedio de tiempo dedicado al pastoreo es mayor en ganado vacuno de carne que en vacas lecheras, lo que estaría posiblemente asociado al tipo de pasturas asignadas a cada tipo de producción.

El concepto de "comida" como la sumatoria de pequeños turnos de consumo fue sugerido por Metz (1975). Gibb et al. (1998) afirman que las SP pueden ser acumulativos y llevar al tiempo total de pastoreo (TTP). Como resultado el tiempo diario que un rumiante pastorea puede ser visto como una sumatoria de turnos. 
Podemos considerar que el tiempo de pastoreo aumenta a medida que disminuye la biomasa o la altura de la pastura (Allden \& Whittaker, 1970; Chacon et al., 1978; Forbes \& Coleman, 1987). Sin embargo, puede no haber respuesta ante pequeñas variaciones en biomasa (Cowan, 1975), es decir que las respuestas no sean proporcionales, y donde el tiempo de pastoreo máximo se obtenga con cantidades intermedias de biomasa (Cowan \& O'Grady, 1976; Hancock, 1952).

El tiempo máximo de pastoreo, se refiere a las situaciones con baja tasa de consumo, donde aparentemente no actuarían los controles físicos y metabólicos del animal. En estos casos, se han considerado los efectos de la fatiga o de la necesidad de disponer de tiempo para otras actividades (Laca et al., 1994; Chacon \& Stobbs 1976; Poppi et al., 1987).

Otros estudios más detallados del comportamiento ingestivo, han hipotetizado que la duración del fotoperiodo es un factor que controla la actividad del pastoreo (Hogan et al., 1987; Linnane et al., 2001). Durante días cortos, las SP pueden concentrarse, originando como consecuencia un incremento en la duración y un menor número de ellas. La preferencia de los animales por pastorear mucho tiempo durante el día se comprueba en el hecho que vacas lecheras en lactancia pastorean aproximadamente 10 hs, en un rango de 9,5 a 11,9 hs (Linnane et al., 2001). El tiempo diario de pastoreo puede incrementarse significativamente desde sus valores normales y posiblemente represente un mecanismo por el cual los rumiantes en pastoreo mantengan un óptimo balance de energía más que lograr un máximo consumo de MS. (Ketelaars \& Tolkamp, 1992)

Según Hodgson (1990), la distribución de los períodos de pastoreo está fuertemente influenciada por los momentos de la salida y la puesta del sol, dando lugar a las SP más largas en torno a esos momentos. Este autor describió que la 
SP más cercana al crepúsculo manifiesta una mayor intensidad y duración (entre 2 a 4 horas) que las de otros momentos del día. Además, hay estudios que demuestran que las SP más cortas y de menor intensidad ocurren durante la noche, representando un bajo porcentaje (6 al $10 \%$ ) del tiempo diario de pastoreo y menos del $4 \%$ del consumo total de MS (O’Connel et al., 1989; Krysl \& Hess, 1993). Resultados similares fueron hallados en varios estudios realizados con vacas y ovejas, donde se demuestra que aproximadamente el $80 \%$ del tiempo dedicado al pastoreo ocurre durante la luz del día y que la proporción de tiempo de pastoreo que sucede durante la noche, se ve incrementada cuando la longitud del día decrece (Penning et al., 1991b; Rook, 2000).

Estos procesos y actividades que se manifiestan durante el pastoreo fueron estudiados en ganado lechero (Gibb et al., 1999.; Chilibroste et al., 1999; Barrett et al., 2001). Sin embargo, en vacunos para carne la investigación en esta temática es aún escasa.

\subsubsection{Momento de asignación diaria de la pastura}

Como se trató en 2.1.3, la materia seca y los carbohidratos no estructurales del forraje aumentan a lo largo del día debido a la pérdida de humedad y a la acumulación de fotosintatos, lo que ocurre mayormente en el sustrato superior del canopeo (Delagarde et al., 2000). Esta variación resulta en un incremento de la digestibilidad (Linnane et al., 2001), palatabilidad (Provenza et al., 1998), y resistencia a la ruptura mecánica por parte de la masticación (Gregorini et al., 2009a) y en la preferencia (Fisher et al., 1999; Burns et al., 2005) por el forraje pastoreado en el crepúsculo. Todo esto cumple un papel importante en la definición del patrón diario de pastoreo y el consumo de nutrientes de los rumiantes. 
A grandes escalas (paisaje; 1-24 meses), las decisiones de pastoreo del animal pueden ser por ejemplo, "dónde" y "cuándo" empezar el pastoreo al inicio de cada uno de las SP (Bailey et al., 1996). Probablemente, la primer decisión sea irrelevante a escalas espacio-temporales pequeñas, como puede ser una parcela diaria, ya que el área está enteramente accesible (Bailey et al., 1996). Las decisiónes relevantes en este caso son "cuándo" las comidas ocurren (Collier \& Johnson, 1990). y durante "cuanto tiempo" se desarrollan las SP y ambas son determinantes de cómo los rumiantes utilizan el tiempo de consumo para cumplimentar sus requerimientos nutricionales.

En relación con esto, el patrón de pastoreo descripto en 2.3.1 para escalas temporales pequeñas (24 horas), interactuaría positiva o negativamente con las decisiones de manejo del operador porque éste condiciona aquellas decisiones del animal. En conclusión la distribución de las SP no sería inexorablemente la descripta arriba, sino que las interacciones con imposiciones externas de manejo o adaptaciones del comportamiento pueden afectarla. Por ejemplo, Orr et al. (2001) modificaron el patrón de pastoreo, aumentando a su vez la producción de vacas lecheras, cuando asociaron el patrón de SP con la variación diurna en la concentración total de CNES.

El pastoreo en franjas diarias no es una técnica aplicada habitualmente a la producción de bovinos para carne, por el aumento del costo que implicaría el cambio diario de parcela frente al manejo tradicional. Pese a ello, incrementos en la producción secundaria como los hallados por Orr et al (2001) podrían llegar a observarse debido a diferencias en el valor nutritivo del forraje en el inicio del patoreo, cuando la parcela cuenta con abundante biomasa, uniformidad y ausencia de excretas. Luego, el momento de inicio del pastoreo (o cambio de parcela) 
durante el día sería una decisión relevante para el operador, cuyo resultado aún debe ser estudiado.

\subsubsection{Efecto del ayuno}

El tiempo entre comidas y el consumo de agua son variables que afectan el hambre, del mismo modo que la secreción de saliva, la fermentación ruminal, la tasa de pasaje y el contenido ruminal (Church, 1989). Este último es la cantidad de forraje presente en el rumen y está determinado por la relación entre el total de forraje consumido y la tasa a la cual dicho forraje abandona el rumen (Hogan et al., 1987). En rumiantes, el llenado ruminal ha sido particularmente relacionado al nivel de hambre (Newman et al., 1994) El grado de hambre actúa sobre la motivación del animal a comer, y este estado afecta muchas de las variables del comportamiento ingestivo (Greenwood \& Demment, 1988; Illius \& Gordon, 1999) y del consumo voluntario de forraje (Patterson et al., 1998; Chilibroste, 1999).

La razón para esperar efectos del hambre sobre el comportamiento ingestivo, está vinculada a la dinámica de la saciedad. Esta fue largamente estudiada, pero poco es lo que se conoce de como, o que grado de condición interna de llenado ruminal afecta el comportamiento ingestivo bajo condiciones de pastoreo. Greenwood \& Dement (1988), hallaron que las tasas de consumo de forraje están normalmente por debajo del máximo posible y que se pueden incrementar con ayunos previos y bajos niveles de llenado ruminal. Posteriormente, Iason et al. (1999) demostraron que con una alta disponibilidad de forraje, el aumento de la tasa de consumo producido por periodos diarios de ayuno, contrarrestaba la reducción de tiempo disponible para pastorear. En igual sentido, Wade et al. (2006) encontraron a su vez que modificando el estado interno de 
vaquillonas de biotipo carnicero a través de periodos de ayuno matutino, se incrementaba el número de bocados por "estación de pastoreo". Asociado a estos cambios del comportamiento ingestivo, el área de pastoreo que los animales exploran dependería del estado interno, como lo demostraron Gregorini et al (2007a).

Existe suficiente evidencia para sugerir que el manejo del llenado ruminal por medio del ayuno, afecta la tasa de consumo voluntario a corto plazo y produce cambios en la dinámica de pastoreo. El relevamiento de información sobre los componentes principales involucrados en la regulación de los procesos de ingestión y digestión bajo pastoreo es esencial no solo para comprender los mecanismos que controlan el consumo voluntario y la eficiencia de aprovechamiento de los nutrientes, sino además para diseñar estrategias de pastoreo y suplementación que permitan realizar un uso eficiente de los recursos alimenticios y animales disponibles. Esto es particularmente relevante en los sistemas pastoriles de nuestro país, donde gran parte de la productividad del sistema se asienta en la eficiencia de producción y utilización del forraje. 


\section{MATERIALES Y MÉTODOS}

\subsection{DESCRIPCIÓN DEL ÁREA DE ESTUDIO}

El estudio fue realizado en el campo experimental "El Amanecer" (3515' 00" de Lat. S y $57^{\circ} 37^{\prime} 30^{\prime \prime}$ de Long. O) El establecimiento posee una superficie de 256,5 ha. y se encuentra a 6,5 km al NO de la localidad de Vieytes, Partido de Magdalena, Provincia de Buenos Aires.

La región posee un clima templado, húmedo, con lluvias durante todo el año. Las precipitaciones presentan una media anual histórica de $950 \mathrm{~mm}$, con un registro máximo de 1470 mm y un mínimo de 490 mm.

En una descripción de los suelos del establecimiento pueden diferenciarse tres Unidades Cartográficas:

Unidad Cartográfica $N^{0} 1$ se desarrolla en los planos más altos del paisaje, sobre lomas aplanadas con vegetación densa. Cubre una superficie de 72,5 ha la que representa el $28 \%$ de la superficie total. El suelo que predomina en estas lomas extendidas, es oscuro, poco profundo y bien drenado, con pendientes suaves del orden del 0,1\%. Dentro del complejo de suelos que forman esta unidad cartográfica, predomina el Argiudol vértico en un $80 \%$ de la superficie.

La Unidad Cartográfica $N^{\circ} 2$ se caracteriza por la presencia de tendidos con micro-relieves cóncavos, charcosos y cañadones. Ocupa una posición media o baja del relieve y una superficie de 156 ha que representa el $61 \%$ del total del establecimiento. Es un suelo con pendientes menores al $0,1 \%$, profundo, pobremente drenado con deficiencias moderadas a graves. Se lo clasifica como Arguidol vértico, el cual predomina en un 60\%. 
La Unidad Cartográfica $N^{\circ} 3$ se desarrolla en las posiciones más deprimidas del paisaje con presencia de bajos, cañadones y cubetas. Ocupa una superficie de 28 ha, que representan el $11 \%$ del total del establecimiento. Dentro del complejo de suelos de esta unidad se encuentra como dominante el Natracualf típico en un 85\% de la superficie. El drenaje de estos suelos es deficiente. El movimiento del agua por escurrimiento es lento. La permeabilidad es muy baja como producto de la presencia de horizontes subsuperficiales con elevados contenidos de arcilla y sodio.

En esta región, donde la principal actividad es la producción pecuaria, los recursos forrajeros los constituyen los pastizales naturales, con un apreciable grado de heterogeneidad. En cuanto a la riqueza florística del lugar, de acuerdo a León et al. (1979), se destaca como dominante la comunidad fitosociológica denominada $\mathbf{B}$. Dicha comunidad se caracteriza principalmente por su alto grado de cobertura, 82\%, dada generalmente por especies gramíneas consideradas buenas forrajeras. Entre ellas las principales son: Paspalum dilatatum, Botrichloa laguroides, Lolium multiflorum, Aristida murina, Setaria geniculata, Stenothaphrum secundatun, Piptochaetium bicolor, P. montevidense, P. stipoides, Bromus mollis, B. unioloides, Briza minor, B. brizoides, B. subaristata, Stipa papposa, S. neesiana, Eragrostis lugens, Agrostis montevidiensis, Melica brasiliana, Vulpia dertonensis, Panicum bergii, Gaudinia fragilis. El valor forrajero de la comunidad se acentúa si se tienen en cuenta las especies leguminosas como Adesmia bicolor, Medicago lupulina y Trifolium repens.

En el área de estudio la variabilidad florística ha sido modificada a través de una promoción de raigrás anual (Lolium multiflorum Lam.), realizada durante tres años consecutivos (2002 a 2004). Este recurso utilizado como verdeo de invierno, 
constituyó la base forrajera sobre la que permanecieron los vacunos durante la etapa en la que se registraron las mediciones (Foto 1).

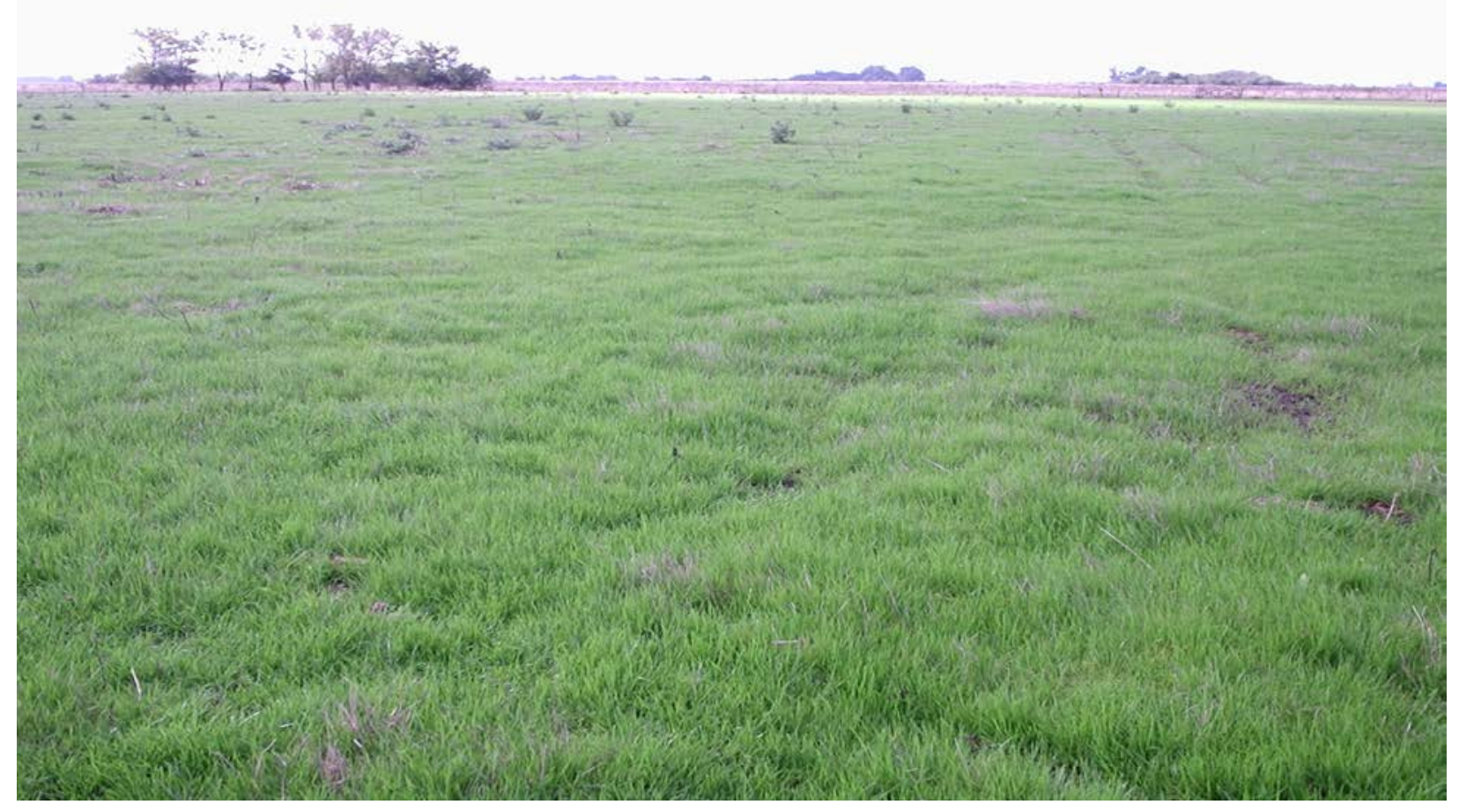

Foto 1: Promoción de raigrás anual (Lolium multiflorum Lam.), utilizada como base forrajera del ensayo.

\subsection{DESARROLLO EXPERIMENTAL}

Para lograr el objetivo planteado en la Introducción, se llevaron a cabo dos experimentos, el Experimento 1 desde el 6 de junio hasta el 13 de octubre de 2004 y el Experimento 2 desde el 7 de Junio al 21 de Septiembre de 2005. Cada experimento abordó un objetivo parcial, que se menciona al inicio de la descripción del mismo.

\subsubsection{Experimento 1}

El objetivo particular del Experimento 1 fue determinar cambios en el patrón diurno de pastoreo y en la performance productiva de vaquillonas carniceras en 
crecimiento, pastoreando una promoción de raigrás anual, cuando la nueva parcela diaria fue asignada a la mañana o a la tarde (momento de asignación diaria).

Mediciones de performance animal y de comportamiento ingestivo fueron conducidas simultáneamente durante el invierno (desde el 6 de junio al 26 de julio) y la primavera (desde el 25 de agosto al 13 de octubre). Para ello se diseñaron dos tratamientos: asignación de forraje matutina (AFM), en la cual los animales fueron conducidos a una nueva parcela a las 7:00 hs cada día, y asignación de forraje vespertina (AFV) donde los animales fueron conducidos a una nueva parcela a las 15:00 hs cada día. En la performance productiva, se evaluó el aumento diario de peso vivo (ADPV), cambios en la nota de condición corporal (NCC), y consumo diario de materia seca de forraje (CMS) en los tratamientos AFM y AFV. En el estudio de comportamiento se midieron los tiempos de pastoreo, rumia y descanso y las tasas de bocados.

\section{a) Generación y caracterización del recurso utilizado}

Para reducir la competencia y favorecer el crecimiento de las especies invernales, 22 ha (área total de experimentación) de campo natural se pulverizaron con 4 I/ha de glifosato a fines de febrero de 2004, y un mes después se fertilizaron con $50 \mathrm{~kg}$ de nitrato diamónico. Como resultado el recurso forrajero utilizado para este experimento fue una promoción de especies invernales, compuesta por un 85 \% de raigrás anual (Lolium multiflorum Lam), determinado por el método de proporción del peso seco (Gillen \& Smith, 1986). Para caracterizar la pastura ademas se midió la altura mediante el uso de regla manual (Barthram, 1986). 


\section{b) Mediciones de calidad del forraje}

Para medir la variación diaria de la composición química del forraje disponible para las vaquillonas, muestras del mismo (150 g de material fresco) fueron tomadas 3 veces al día (7:00 hs, 13:00 hs y 19:00 hs) correspondiendo con los más importantes SP de los animales (Gibb, 1998; Taweel, 2004). Los muestreos se realizaron una vez a la semana, durante tres semanas en cada estación (invierno y primavera). Las muestras se tomaron siguiendo una metodología de hand-plucking, similar a la descripta por Smit et al. (2005), caminando cerca de 4 animales, elegidos al azar, y tomando muestras cortadas a mano, imitando los movimientos de aprehensión del pasto de los mismos, dónde y cuándo pastorean, pero en lugares sin pastorear. Luego de tomadas las muestras fueron conservadas en freezer $\left(\mathrm{a}-20^{\circ} \mathrm{C}\right)$ y posteriormente unificadas por momento del día, secadas en estufa $\left(\mathrm{a} 60^{\circ} \mathrm{C}\right)$ por $48 \mathrm{hs}$, molidas y tamizadas a $2 \mathrm{~mm}$., efectuándoseles los siguientes análisis: Fibra detergente neutro (FDN) de acuerdo a la técnica de Van Soest et al. (1991); Carbohidratos no estructurales solubles (CNES) con el método de la antrona (Yemm \& Willis, 1954); Proteina Bruta (PB) $(6.25 \times \mathrm{N})$ usando micro Kjeldhal (Bremner \& Mulvaney,1982); Digestibilidad in vitro de la MS ( DIVMS) de acuerdo a Tilley \& Terry (1963).

\section{c) Mediciones de performance productiva}

Se seleccionaron por peso y condición corporal 48 vaquillonas de un total de 60 (foto 2), descartando animales muy livianos o muy pesados en relación a la edad y animales de baja condición corporal. Los pesos al inicio del ensayo en 
invierno fueron: $183 \pm 26 \mathrm{~kg} \mathrm{NCC}=5.6 \pm 0.02$ (con una escala de 1 a 9 puntos) $\mathrm{y}$ en primavera: $246 \pm 23 \mathrm{~kg} \mathrm{NCC:} 6.1 \pm 0.13$.

Fueron alimentadas utilizando un método de pastoreo rotativo en franjas diarias. A lo largo del experimento, las parcelas diarias fueron pastoreadas siempre en estado vegetativo (3-4 hojas verdes por macollo). La asignación de forraje fue del $6 \%$ del peso vivo de los animales, base materia seca. El tamaño de las parcelas diarias fue determinado de acuerdo a la disponibilidad de materia seca de forraje $(\mathrm{kg} / \mathrm{ha})$ y la asignación. La disponibilidad de forraje fue determinada semanalmente, por medio de 9 cortes para cada tratamiento, con un cuadro de superficie conocida $(30 \times 30 \mathrm{~cm}$.) con tijera manual y a una altura de remanente de $3 \mathrm{~cm}$. El forraje cosechado fue pesado y se extrajeron muestras para la determinación de su contenido de materia seca.

Cada parcela fue delimitada mediante el uso de alambrado eléctrico, práctica de uso común en la zona. Las vaquillonas no fueron provistas de agua a voluntad, debido al alto contenido de agua en el forraje. Las necesidades de consumo de agua en bovinos para carne calculados con la ecuación de Winchester y Morris (1956), o con las ecuaciones de predicción del NRC (1984), arrojan resultados de 20-22 I/día, para las terneras utilizadas en el ensayo y bajo las condiciones de temperatura y alimentación en las que transcurrió el experimento. Estas necesidades pudieron ser satisfechas con el agua que aportó el alimento durante los distintos momentos del ensayo, ya que un consumo de entre 4 y $6 \mathrm{~kg}$ de promoción de raigrás anual con 16 a $20 \%$ de MS, aportaría 22-24 I de agua,

Quince días antes del comienzo del experimento en otoño y primavera los animales fueron conducidos a pastorear todos juntos y con cambios de la parcela diaria a las 11:00 hs cada día. Luego de este período de acostumbramiento, fueron 
distribuidos al azar a los tratamientos AFM y AFV. El lapso de medición fue de 5 semanas en invierno y 5 semanas en primavera. Al cabo del primer período los animales se transladaron a una pastura polifítica contigua, y antes de iniciar el período de primavera fueron nuevamente distribuidos al azar en dos lotes de similar peso promedio.

Los animales fueron pesados y fue determinada su NCC, semanalmente. Para minimizar las diferencias en el llenado ruminal, la pesada de los animales se realizó inmediatamente antes de ser cambiados a una nueva parcela diaria, de acuerdo al tratamiento (7:00 hs para el tratamiento AFM y 15:00 hs para AFV).

El consumo de materia seca fue estimado por el método de cortes de ofertaremanente $($ consumo $=$ disponibilidad inicial - remanente/ número de animales) (Meijs, 1981). Durante el experimento, y exclusivamente para la estimación de consumo, fue determinada la disponibilidad inicial de forraje fresco y su contenido de MS, en una parcela diaria por semana antes del pastoreo, a través de 9 cortes manuales por tratamiento, a una altura constante de $3 \mathrm{~cm}$, de un cuadro de superficie conocida $(30 \mathrm{~cm} \times 30 \mathrm{~cm})$. El remanente de forraje fue determinado en esa misma parcela después del pastoreo con 9 cortes por tratamiento, con un cuadro de $30 \mathrm{~cm}$ x $30 \mathrm{~cm}$ (Meijs, 1981; Smit et al., 2005). El forraje cosechado fue pesado y una muestra fue utilizada para la determinación del contenido de MS (en estufa a $60^{\circ} \mathrm{C}$ hasta peso constante). 


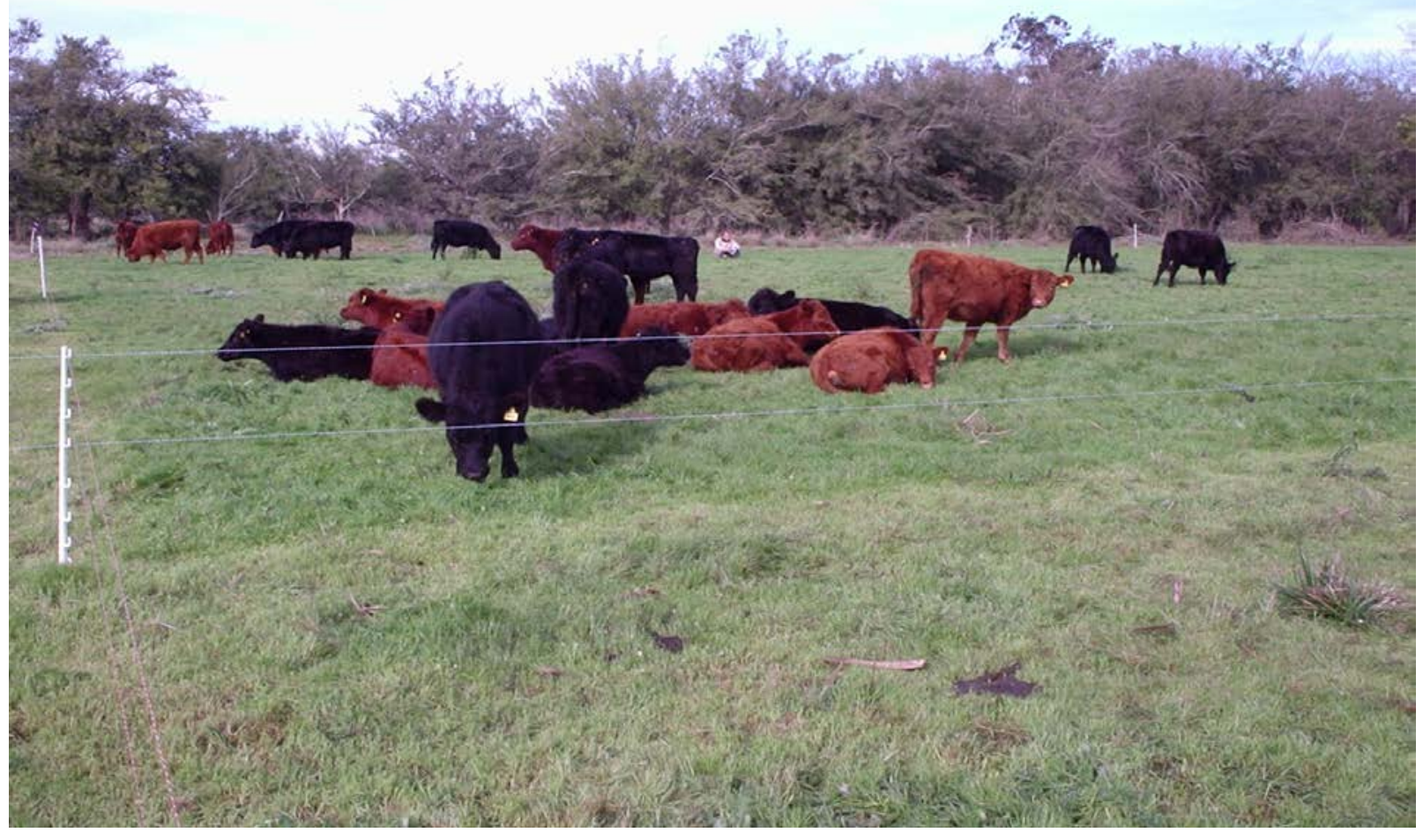

Foto 2: Terneras Aberdeen Angus utilizadas en el ensayo.

\section{d) Mediciones de comportamiento ingestivo}

Ocho vaquillonas Aberdeen Angus, 4 por tratamiento (Peso inicial en el período de Invierno: $183 \pm 2.1 \mathrm{~kg}$ y en primavera: $254 \pm 7.5 \mathrm{~kg}$ ), fueron seleccionadas (como animales focales) para realizar sobre ellas las mediciones de comportamiento ingestivo. Estos animales permanecieron dentro del grupo de animales correspondiente a cada tratamiento y fueron manejadas de la misma forma descripta en el estudio de performance productiva. Para los animales seleccionados se usó un diseño experimental cross-over simple (Jones \& Kenward, 1989) con 2 sub-períodos de observación dentro de cada período del ensayo (invierno y primavera) y dos tratamientos (AFM y AFV). Cada sub-período consistió en 10 días de adaptación a la dieta, tratamiento, manejo y presencia de 
observadores individuales y un día de medición del comportamiento. Finalizado el primer subperíodo los 4 animales de cada tratamiento se transfirieron al tratamiento opuesto. Pastoreo, rumia y descanso fueron determinados visualmente, cada dos minutos (Hirata et al., 2002) desde la 7:00 hs hasta las 19:00 hs, por dos observadores entrenados, que fueron distribuidos al azar en cada tratamiento y período. Los tiempos de pastoreo, rumia y descanso fueron calculados multiplicando la frecuencia de cada comportamiento por el intervalo de 2 minutos. Para visualizar gráficamente, la distribución de las SP, intervalos de no actividad de pastoreo mayores a 5 minutos de duración fueron considerados como límite final de una SP. Intervalos menores a 5 minutos de interrupción de la actividad de pastoreo fueron considerados como interrupciones intra SP (Rook et al., 1994). Para el propósito de este estudio, una SP no es exactamente un periodo de tiempo en que el animal está solo comiendo, sino un período en el que el animal desarrolla todas las actividades que están relacionadas con la acción de comer, como son búsqueda, introducción del alimento en la boca, masticación y tragado del forraje (Gibb et al., 1998). El tiempo diurno de cada comportamiento fue resumido para tres períodos del día: Mañana (7:00 hs a 11:00 hs) mediodía (11:00 hs a 15:00 hs) y tarde (15:00 hs a 19:00 hs). Para medir la tasa de bocado (bocados por minuto) ocho observadores entrenados fueron distribuidos al azar para medir cada animal en cada período. La tasa de bocado fue determinada al principio, medio y final de cada momento del día en por lo menos 5 períodos de un minuto de actividad de pastoreo. 


\section{e) Análisis estadístico}

En el experimento de performance productiva fue utilizado un diseño completamente aleatorizado (Gill, 1978) con las vaquillonas como unidad experimental. El ADPV y los cambios en NCC, fueron analizados usando modelos estadísticos que incluyen el efecto del tiempo, como medidas repetidas, con PROC MIXED de SAS (SAS Inst. inc., Cary. NC). El error usado en este análisis para testear el efecto tratamiento, fue la vaquillona dentro del tratamiento $\mathrm{X}$ semana. El error residual fue utilizado para verificar el efecto del tiempo y las interacciones con el mismo. Las interacciones entre tiempo y tratamiento fueron testeadas utilizando el análisis de medias de cuadrados mínimos.

La biomasa, la altura de la pastura, el consumo de MS, tiempo de pastoreo, rumia y descanso y tasa de bocado, fueron analizados con ANOVA, utilizando GLM de SAS (SAS Inst. inc. Cary. NC). En biomasa, altura de la pastura y consumo de MS, la semana fue tomada como fuente de variación. En las variables de comportamiento y en la variación diaria de la composición química del forraje disponible para las vaquillonas, momento del día fue considerado como tratamiento. Mínimos cuadrados medios fueron separados usando la opción Pdiff en SAS (SAS Inst. inc. Cary. NC). Un efecto fue considerado significativo cuando $\mathrm{P}<0.05$. 


\subsubsection{Experimento 2}

El objetivo particular del Experimento 2 fue asociar al manejo de parcelas diarias con asignación vespertina un período de ayuno matutino y determinar si la estimulación del consumo vespertino, así inducida, podría directamente afectar la performance animal.

Estudios de performance productiva y comportamiento ingestivo fueron conducidos simultáneamente. Parcelas de raigrás anual (que constituyó el 88 \% de la MS), utilizadas mediante pastoreo en franjas, fueron asignadas diariamente en la tarde a vaquillonas carniceras (los animales fueron conducidos a una nueva parcela a las 14:30 hs), con ayuno previo de $8 \mathrm{~h}$ desde las $6: 30$ hs a las 14:30 hs cada día (AY) o sin ayuno previo de 8 h (SINAY). Los animales del tratamiento (AY) fueron mantenidos en un corral de $625 \mathrm{~m}^{2}$ a $50 \mathrm{mts}$ de las parcelas diarias, sin acceso a pasto o suplemento de ningún tipo. El estudio de performance productiva, evaluó ADPV, cambios en la NCC y estimó el consumo de materia seca de los animales bajo los mismos tratamientos (AY y SINAY). Las investigaciones de comportamiento analizaron los tiempos de pastoreo, rumia y descanso durante las horas del día (6:30 a 18:30 hs) y la tasa de bocado (desde las 14:30 a 18:30 hs).

Durante este experimento 2 las medias de temperatura diaria, radiación y precipitaciones fueron respectivamente $12,5^{\circ} \mathrm{C} ; 1864$ Wat $/ \mathrm{m}^{2}$ y $52,1 \mathrm{~mm}$ para los 4 meses. 


\section{a) Caracterización del recurso utilizado}

El recurso utilizado, una promoción química de especies invernales, fue conducido y fertilizado de la forma descripta en el experimento 1, logrando una pastura con $88 \%$ de raigrás anual, (Lolium multiflorum Lam), contenido determinado por el método de proporción del peso seco (Gillen \& Smith, 1986).

\section{b) Mediciones de calidad del forraje}

Para realizar las mediciones de biomasa de la pastura, y aquellas necesarias para determinar la variación de la composición química del forraje disponible para los animales se procedió de la forma descripta en el experimento previo.

\section{c) Mediciones de performance productiva}

Para este estudio se utilizaron 58 vaquillonas Aberdeen Angus ( $P V=189.54$ $\pm 0.26 \mathrm{~kg}$ y $\mathrm{NCC}=5.49 \pm 0.18)$ que pastorearon en forma rotativa una pastura natural hasta 10 días antes de comenzar el ensayo. A partir de allí, fueron conducidas en pastoreo intermitente en franjas asignadas diariamente a las 11:00 hs, sobre una pastura dominada por raigrás anual. Luego de este período de acostumbramiento a la dieta, las vaquillonas fueron asignadas al azar a los tratamientos AY y SINAY, empleando un diseño completamente aleatorizado (Gill, 1978). Inicialmente, se realizó un período de adaptación al manejo de cada tratamiento durante una semana, y a partir de allí comenzó el período de mediciones de 14 semanas. Las vaquillonas pastorearon de acuerdo a los tratamientos parcelas totalmente separadas (los animales no se podían ver), 
usando el método de franjas diarias a lo largo del experimento. Las parcelas diarias estaban siempre en estado vegetativo (entre 3 y 4 hojas por macollo). La asignación de forraje fue del $6 \%$ del peso vivo (base MS). Así, la superficie de la parcela fue determinada de acuerdo a la biomasa y disponibilidad de MS (kg/ha). La biomasa de forraje fue determinada semanalmente al atardecer, por medio de 9 cortes para cada tratamiento, realizados con cuadros de $30 \times 30 \mathrm{~cm}$, con tijeras manuales y a una altura constante de $3 \mathrm{~cm}$. El forraje cosechado fue pesado y se tomaron muestras para la determinación de MS, secándolas en estufa a $60^{\circ} \mathrm{C}$ durante 48 hs. Manteniendo las condiciones de manejo propias de la región (Pampa Deprimida), las vaquillonas no tuvieron acceso a ninguna instalación de reparo, ni suplementación con minerales, y en este caso tampoco libre acceso al agua, debido al alto contenido de humedad del forraje (79 \%).

Los animales fueron pesados y determinada su NCC (con una escala de 1 a 9) cada 2 semanas. Para minimizar las diferencias en el llenado ruminal, todas las pesadas fueron realizadas a las 5:30 hs, antes que los animales asignados al tratamiento AY, comenzaran dicho período (6:30 hs). El consumo voluntario de MS de cada grupo de animales (AY y SINAY) fue estimado cada 2 semanas, con el método del corte (desaparición del forraje): Biomasa disponible antes del pastoreo menos biomasa de forraje después del pastoreo o remanente (con 9 cortes para cada tratamiento de un cuadro de $30 \times 30 \mathrm{~cm}$, con tijera manual a $3 \mathrm{~cm}$ de altura). Estas muestras fueron tomadas entre las 14 y 14:30 hs, y se determinó en ellas su contenido de MS (con estufa a $60^{\circ} \mathrm{C}$ durante 48 hs). 


\section{d) Mediciones de comportamiento ingestivo}

Ocho vaquillonas adicionales (4 por tratamiento), Aberdeen Angus (PV = 192 $\pm 1.67 \mathrm{~kg}$ ) fueron incorporadas como animales focales y manejadas de la misma forma descripta en el estudio de performance productiva. Se usó un diseño experimental cross-over simple (Jones y Kenward, 1989) con 2 períodos y dos tratamientos. Las vaquillonas fueron distribuidas al azar en cada tratamiento (AY y SINAY). Cada período consistió en 10 días de adaptación a la dieta, tratamiento, manejo y presencia de observadores individuales, y un día de medición de comportamiento. Pastoreo, rumia y descanso fueron visualmente determinados cada 2 minutos (Hirata et al., 2002) desde las 6:30 hs hasta las 18:30 hs por dos observadores entrenados que fueron asignados al azar en cada tratamiento y período. Con esos datos fueron calculados los tiempos totales de pastoreo, rumia y descanso, multiplicando la frecuencia de cada comportamiento por el total de intervalos de 2 minutos. Para determinar y visualizar gráficamente la distribución de las SP, detenciones en la actividad de pastoreo de más de 5 minutos, fueron considerados como límite de un turno de pastoreo, e intervalos menores a 5 min. fueron considerados descansos intra-evento (Rook \& Hukcle, 1997). De acuerdo al objetivo de este estudio, la actividad fue considerada pastoreo cuando los animales estaban abocados a las tareas de aprehender el forraje, masticación e ingestión del bolo alimenticio, así como también a las tareas de búsqueda a nivel de estaciones de pastoreo. Para la medición de la tasa de bocado (bocados por minuto), se asignó al azar un observador entrenado a cada animal y en cada período. La tasa de bocado fue determinada en cada SP del período vespertino (desde las 14:30 hs hasta las 18:30 hs) durante lapsos de 1 minuto de actividad de pastoreo continua. 


\section{e) Análisis estadístico}

El ADPV y los cambios en NCC, fueron analizados usando modelos estadísticos que incluyen el efecto del tiempo, como medidas repetidas, con PROC MIXED de SAS (SAS Inst. inc., Cary. NC). El error usado en este análisis para testear el efecto tratamiento, fue la vaquillona dentro del tratamiento $X$ tiempo. El error residual fue utilizado para verificar el efecto del tiempo y las interacciones con el mismo. Las interacciones entre tiempo y tratamiento fueron testeadas utilizando el análisis de medias de cuadrados mínimos. La biomasa, la altura de la pastura, pastoreo diario y vespertino, rumia, tiempo de descanso, tasa de bocado, así como el Consumo de MS, fueron analizados con ANOVA, utilizando GLM de SAS (SAS Inst. inc. Cary. NC). En el caso de la variación diaria de la composición química del forraje disponible para las vaquillonas, momento del día fue considerado como tratamiento. Mínimos cuadrados medios fueron separados usando la opción Pdiff en SAS (SAS Inst. inc. Cary. NC). Un nivel de significancia de $P<0.05$ fue considerado significativo. 


\section{RESULTADOS Y DISCUSIÓN}

\subsection{EXPERIMENTO 1}

\section{Calidad de forraje}

Los promedios de disponibilidad de forraje y de altura de la pastura fueron de $2.477 \pm 418 \mathrm{~kg}$ de MS/ha y $23,46 \pm 2.07 \mathrm{~cm}$ en el período invernal, y $2.641 \pm$ $566 \mathrm{~kg}$ de MS/ha y 23,66 $\pm 3.04 \mathrm{~cm}$ para la primavera $(P>0.05)$. La DIVMS fluctuó durante las horas del día encontrándose siempre los menores valores a las 7:00 hs. La DIVMS en invierno fue entre 7 y 8 unidades porcentuales superior a la de primavera $(\mathrm{P}<0.05)$ (Tabla 1$)$. Estas diferencias podrían explicarse por la relación hoja: tallo (Laredo \& Minson, 1975) y la fenología de las plantas en ambas estaciones (Van Soest, 1982). Durante el invierno, las vaquillonas siempre utilizaron parcelas que no habían sido previamente pastoreadas, y por su estado vegetativo debieron encontrar una mayor relación hoja-tallo que en primavera. Además en esta estación pudo haber un incremento del material senescente en relación a los valores del invierno.

La composición química del forraje (FDN, CNES, y PB) varió con el correr de las horas del día $(P<0.05)$, pero no entre estaciones. Entre la mañana y la tarde la FDN disminuyó un $11 \%$ y los CNES aumentan un $35 \%$, mientras que la PB, decreció numéricamente en forma no significativa (Tabla 1). 
Tabla 1. Variación de la composición química (\% de MS) durante la horas del día del forraje de una promoción de raigrás, consumido por vaquillonas en un pastoreo intermitente en franjas diarias ${ }^{1}$

\begin{tabular}{|c|c|c|c|c|c|c|c|c|c|c|c|c|}
\hline Variable & \multicolumn{3}{|c|}{$D^{\prime} V M S^{2}$} & \multicolumn{3}{|c|}{$F D N^{3}$} & \multicolumn{3}{|c|}{ CNES $^{4}$} & \multicolumn{3}{|c|}{$P B^{5}$} \\
\hline estación & invierno & Primav. & $\mathrm{ES}^{6}$ & invierno & Primav. & ES & invierno & Primav. & ES & invierno & Primav. & ES \\
\hline Hora del día & & & & & & & & & & & & \\
\hline $7: 00$ & $79^{\text {ax }}$ & $72^{\mathrm{bx}}$ & 2.4 & $50^{x}$ & $46^{x}$ & 2.2 & $13.6^{x}$ & $10.3^{x}$ & 2.78 & 15.2 & 14.4 & 1.02 \\
\hline $13: 00$ & $81^{\text {axy }}$ & $74^{\mathrm{bxy}}$ & 2.4 & $47^{y}$ & $43^{x y}$ & 4.2 & $18.1^{y}$ & $16.2^{y}$ & 2.78 & 13.2 & 12.4 & 1.22 \\
\hline 19:00 & $83^{a y}$ & $75^{\text {by }}$ & 2.5 & $46^{z}$ & $40^{y}$ & 4.3 & $20.3^{y}$ & $16.3^{y}$ & 2.85 & 14.3 & 12.9 & 1.41 \\
\hline ES & 1.7 & 1.7 & & 3.0 & 3.0 & & 1.97 & 2.01 & & 1.5 & 1.4 & \\
\hline
\end{tabular}

${ }^{1}$ Los valores son los promedios de tres fechas de muestreo en cada estación, confeccionando muestras compuestas en cada horario a través del seguimiento de 4 animales.

${ }^{2}$ DIVMS. Digestibilidad in vitro de la materia seca

${ }^{3}$ FDN. Fibra detergente neutro

${ }^{4}$ CNES Carbohidratos no estructurales

${ }^{5}$ PB. Proteina bruta

${ }^{6}$ ES. Error estandad

a,b, Entre variables de una fila. Valores con diferente letra presentan diferencias significativas $(P<0.05)$

$x, y, z^{-}$Entre variables de una columna. Valores con diferente letra presentan diferencias significativas $(P<0.05)$

Estos valores de composición química son similares a los obtenidos por Delagarde et al. (2000), quienes reportan que en pastoreo rotativo de raigrás perenne (Lolium perenne L.), el momento del día tiene efectos significativos en la FDN y el contenido de CNES. Particularmente para el forraje localizado por encima de los $10 \mathrm{~cm}$ del suelo, estos autores obtuvieron desde el amanecer al atardecer una disminución de $25 \mathrm{~g}$ de FDN y un incremento de $40 \mathrm{~g}$ en CNES, por kg de materia orgánica. Griggs et al. (2005) compararon la concentración de CNES, en secuencias de cortes de 24 hs, en pasto ovillo (Dactilis glomerata L.). A pesar de la 
pequeña diferencia encontrada (los promedios para octubre, junio y agosto fueron de 7,6 $\pm 3.9 \mathrm{~g} / \mathrm{kg} \mathrm{MS}$ ), sugieren un potencial incremento en horas del atardecer. Delagarde et al. (2000) puntualizan que esa fluctuación en la concentración de CNES ocurre primero en estratos de la vegetación donde se producen intercambios gaseosos y representan sitios fotosintéticamente activos. Mayland et al. (2003) demuestran que esa fluctuación mayormente ocurre en las hojas, y que las que están expuestas a 15 hs de luz, tenían 1,6 veces más concentración de azúcares, que hojas expuestas a 9 hs de oscuridad. En heno de alfalfa (Medicago sativa L.) cortado durante la tarde, Fisher et al. (2002) encontraron un descenso del $5 \%$ en FDN y un incremento del $18 \%$ en CNES con respecto al mismo material cortado a la mañana. Burns et al. (2005) compararon la calidad del heno de alfalfa cortado al atardecer de un día soleado, versus el obtenido con cortes matutinos, encontrando que el primero tenía $2 \%$ menos de FDN y $22 \%$ más de CNES.

Estos resultados y los obtenidos en este trabajo sostienen la premisa de que el cambio en la composición química de las plantas que ocurre entre horas del día es debido a un incremento en los fotosintatos, lo cual conduce a una dilución pasiva de la FDN y la PB y a un aumento en la concentración de CNES (Delagarde et al., 2000).

En rumiantes en pastoreo las mayores pérdidas de $\mathrm{N}$ en el rumen son generalmente observadas cuando consumen pasturas tiernas y foliosas debido al alto consumo de proteína soluble (Van Vuuren, 1993). Una gran concentración de amonio ruminal se encuentra generalmente durante el evento de pastoreo del amanecer que conduce a un desbalance entre la concentración de amonio y la disponibilidad de carbohidratos rápidamente fermentecibles (Chilibroste et al., 2005). Este desbalance restringe la actividad de la población microbiana del rumen, 
que es menor a esa hora del día. Esta situación nos lleva a puntualizar que bajo condiciones de pastoreo, la provisión de nutrientes a los microorganismos ruminales varía en los distintos eventos de pastoreo a lo largo del día. No solo la provisión total, sino también el balance de los mismos. Es así que el valor nutritivo y el valor alimenticio del forraje deben ser diferenciados de acuerdo al momento del día en que ese forraje se utilice. Por lo tanto el manejo del pastoreo que induzca a un evento de pastoreo más intenso al atardecer debería aumentar la performance animal.

\section{Consumo y Performance productiva}

El efecto tratamiento $x$ semana fue altamente significativo para ADPV $(P<$ 0,01) y NCC $(P<0,01)$ en el período de cinco semanas de medición correspondientes al invierno. El análisis de la interacción muestra que las vaquillonas en el tratamiento AFV, ganaron más peso y tuvieron una mejor NCC, desde la semana 3 a la $5(P<0,05)$ que las vaquillonas del tratamiento AFM (Figura 3). El promedio de ADPV de las semanas 3 a 5 fue 863 vs. 713 g para AFV y AFM respectivamente. No hubo diferencias significativas en la interacción tratamiento $x$ semana en la primavera $(p=0.74)$. Cabe mencionar que diferencias entre ADPV comienzan a aparecer desde la semana 1 de esta estación (Figura 4). El promedio de ADPV del período fue $963 \mathrm{~g}$ para las vaquillonas en AFV vs $623 \mathrm{~g}$ para las vaquillonas del tratamiento AFM. Además, las primeras aumentaron en promedio 0.0145 puntos más de NCC $(\mathrm{P}<0,05)$ 
Figura 3: Aumento diario de peso vivo de vaquillonas para carne, en pastoreo rotativo en franjas diarias, durante el invierno, con Asignación de forraje matutina (AFM, 7:00 hs) o vespertina (AFV, $15: 00$ hs). ${ }^{a, b}$ Valores en la misma semana con diferente letra difieren estadísticamente $(p<0.05)$.

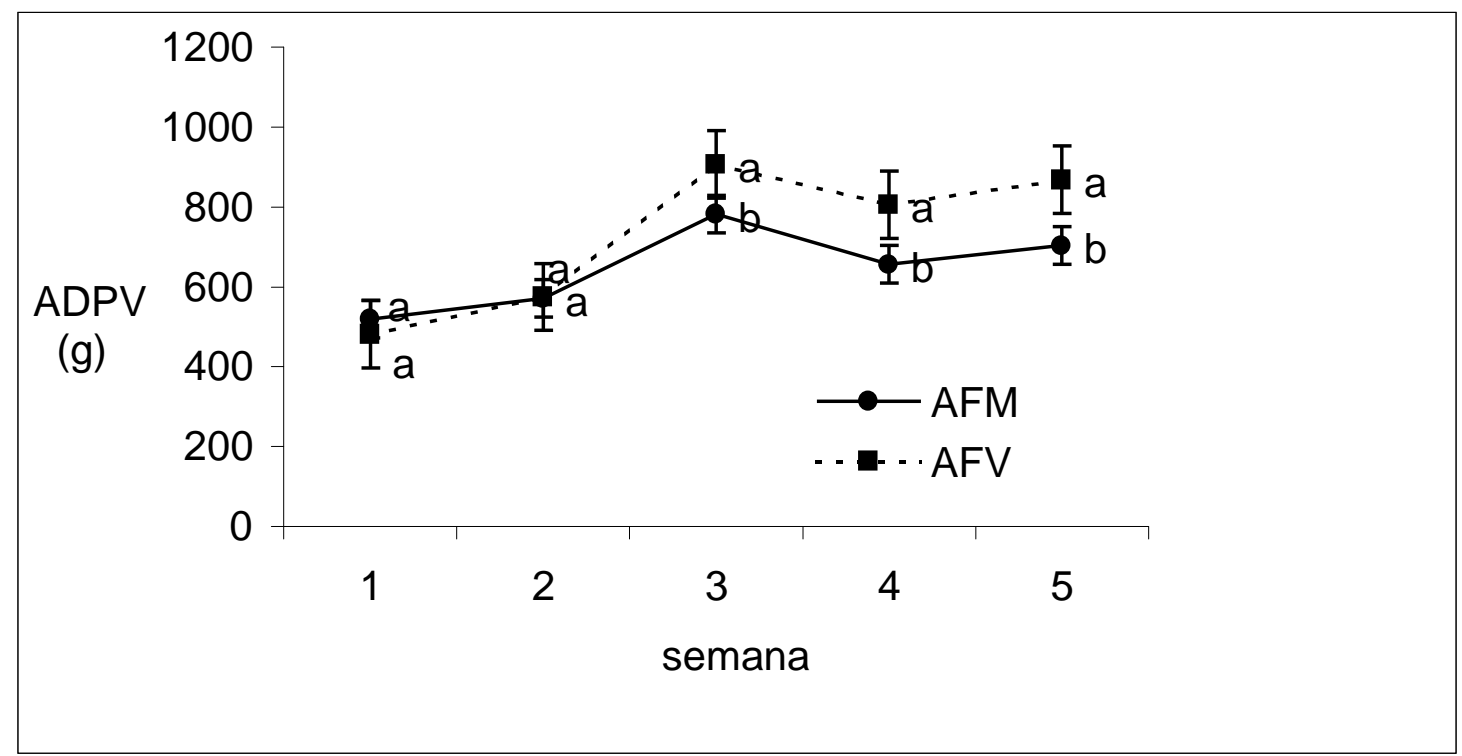

Figura 4: Aumento diario de peso vivo de vaquillonas para carne, en pastoreo rotativo en franjas diarias, durante la primavera, con Asignación de forraje matutina (AFM, 7:00 hs) o vespertina (AFV, $15: 00 \mathrm{hs}) .{ }^{\mathrm{a}, \mathrm{b}}$ Valores en la misma semana con diferente letra difieren estadísticamente $(p<0.05)$.

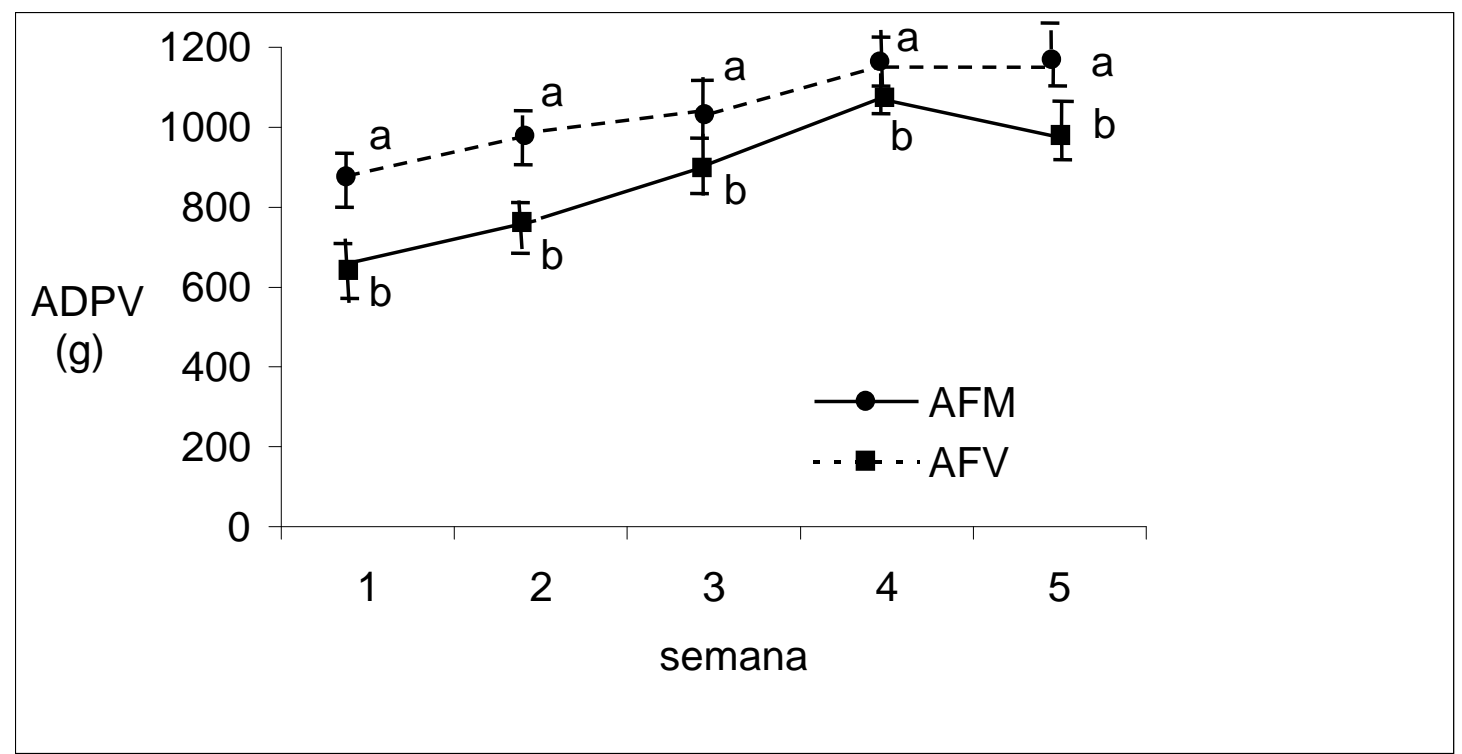


Aún siendo diferente el tipo de animal, los resultados con respecto a la performance productiva siguen la misma tendencia encontrada por Orr et al. (2001), con pastoreo en franjas diarias de vacas lecheras, ofreciendo las nuevas franjas después del ordeñe matutino y vespertino. Ellos no encontraron diferencias en la producción de leche a través de un período de 10 semanas, aunque gradualmente se comenzaba a diferenciar $(P=0.07)$ en las últimas 4 semanas. Dalley et al. (2001) asignando la nueva parcela 1 o 6 veces diariamente, reportan una disminución en la producción de leche en el grupo con más frecuencia de asignación de forraje. (26,7 y 25,7 // vaca diarios respectivamente). La menor producción, puede ser causada por el consumo de forraje con menos contenido de CNES, durante los períodos nocturnos de pastoreo, ya que dos de las parcelas se asignaban después de las 21:00 hs.

A pesar de los diferentes momentos de asignación del forraje, las vaquillonas en este trabajo, tuvieron el mismo consumo de MS en el invierno (AFV: 5.0 vs. AFM: $4,5 \mathrm{~kg}$ de MS diarios, $\pm 1.48 ; \mathrm{P}=0.35)$ y en primavera (AFV: 5.6 vs. AFM: $5.1 \mathrm{~kg}$ de MS diarios, $\pm 0.80 ; \mathrm{P}=0.35)$, confirmando lo reportado por Orr et al. (2001). No obstante, el consumo diario de energía de las vaquillonas debió haber diferido ya que la DIVMS fue en promedio $4 \%$ mayor en el horario del atardecer (19:00 hs) vs el amanecer (07.00) en invierno, y $3 \%$ en la primavera (Tabla 1). Esta presunción es sostenida además por el mayor valor nutritivo encontrado por Griggs et al. (2005) con patrones de defoliación simulados en pasturas de pasto ovillo y Burns et al. (2005) y Fisher et al. (1999; 2002) quienes utilizaron heno de alfalfa y festuca alta (Festuca arundinacea Screb.) cortados al amanecer o al atardecer. 
Además, en el presente trabajo las vaquillonas del tratamiento AFV se encontraron con una parcela rebajada durante la mañana y el mediodía, lo cual puede haber causado un menor consumo durante esos períodos y por lo tanto reducido el llenado ruminal al momento de entrar en la nueva parcela. Esto generó una mayor tasa de consumo en el horario vespertino, ya que aún a una misma tasa de bocado es esperable una mayor masa de bocado. (Gregorini et al., 2006).

\section{Comportamiento ingestivo}

El análisis del estudio de comportamiento (Tablas 2 y 3) muestra que en el tratamiento AFV disminuye el tiempo de pastoreo $(T P)$ diurno $(P<0.01)$ comparado con AFM, independientemente de la estación de que se trate. En AFM los animales pastorearon 63 y 54 min más que en el tratamiento AFV durante las horas del día, en invierno y primavera respectivamente. Este resultado difiere de los tiempos de pastoreo reportados por Orr et al. (2001) en vacas lecheras suplementadas y bajo diferente longitud del día, las cuales pastorearon el mismo rango de tiempo independientemente del momento de asignación. Los eventos de pastoreo pueden considerarse acumulativos, conduciendo al tiempo diario de pastoreo (Gibb, 1998). Como resultado, el tiempo diario de pastoreo puede ser visto como la suma de algunos eventos de pastoreo. En pastoreo en parcelas diarias, las decisiones concernientes al pastoreo, como por ejemplo, cuándo empezar, con qué frecuencia y hasta cuándo extender el evento de pastoreo, determinan cómo los bovinos ordenan el tiempo invertido en alimentarse y encontrar los nutrientes necesarios para cubrir sus requerimientos metabólicos. Analizando el patrón de pastoreo se comprueba que la frecuencia de eventos de pastoreo (Figuras 5 y 6) y la distribución del tiempo de pastoreo no son completamente inflexibles y que un 
simple cambio en el momento de asignación del forraje puede modificar el momento en que el pastoreo se produce, particularmente bajo un sistema de pastoreo en parcelas diarias. De acuerdo con los datos presentados en las Tablas 2 y 3 , las vaquillonas con AFV concentraron el $54 \%$ y el $50 \%$ de su tiempo diurno de pastoreo en las 4 horas del final de la tarde, en invierno y primavera respectivamente. Además en ese momento mostraron una mayor tasa de bocado $(P<0.01)$. En el tratamiento AFM utilizaron el $39 \%$ del tiempo diurno de pastoreo en invierno y el $36 \%$ durante la primavera en la mañana, cuando el forraje muestra mayores dificultades para que los animales logren un mayor consumo, por un menor contenido de MS (Van Soest, 1982), mayor humedad superficial (Gibb et al., 1998) y una baja relación CNES:PB (Chilibroste et al., 2005). En AFV el porcentaje del tiempo diurno de pastoreo utilizado en la mañana, fue del $25 \%$ en invierno y el $28 \%$ en primavera. Por otra parte, la tasa de bocado a la mañana en los animales del tratamiento AFM frente a los animales del tratamiento AFV fue 1.4 y 1.3 veces mayor en primavera e invierno respectivamente.

Investigaciones realizadas por Orr et al. (2001), mencionadas arriba, demuestran que vacas lecheras, en parcelas diarias asignadas al atardecer, presentaban un mayor evento de pastoreo vespertino (4 hs vs. 3 hs) y destinaban menos tiempo diurno a la rumia. En nuestro estudio, el tiempo de rumia varió de acuerdo al momento del día, pero el tiempo total de rumia diurno no varió (invierno, $P=0.43$; primavera $=0.23$ ), lo que implica que el efecto de los tratamientos se observa en el patrón de rumia diurno: en el tratamiento AFV los tiempos de rumia y descanso diurnos se concentraron durante la mañana y el mediodía 
Tabla 2. Tiempos de pastoreo, rumia y descanso (minutos), y tasa de bocado (bocados/min en cada momento del día) de vaquillonas para carne pastoreando franjas diarias en invierno, con asignación de forraje vespertina (AFV) y matutina (AFM)

\begin{tabular}{|c|c|c|c|c|c|c|c|c|c|c|c|c|}
\hline Variable & \multicolumn{3}{|c|}{ Tiempo de pastoreo } & \multicolumn{3}{|c|}{ Tiempo de rumia } & \multicolumn{3}{|c|}{ Tiempo de descanso } & \multicolumn{3}{|c|}{ Tasa de bocado } \\
\hline Tratamiento & AFV & AFM & $\mathrm{ES}^{1}$ & AFV & AFM & ES & AFV & AFM & ES & AFV & AFM & $\overline{E S}$ \\
\hline $\begin{array}{c}\text { mañana } \\
\text { 07:00 a 11:00 }\end{array}$ & $76^{\times a}$ & $137^{\text {ya }}$ & 10.5 & $12^{x a}$ & $20^{\text {ya }}$ & 5.1 & $121^{x a}$ & $60^{\text {ya }}$ & 11.2 & $28^{x a}$ & $40^{\text {ya }}$ & 9.8 \\
\hline $\begin{array}{c}\text { mediodía } \\
\text { 11:00 a 15:00 }\end{array}$ & $58^{\times a}$ & $91^{\text {yb }}$ & 8.3 & $57^{\times b}$ & $43^{y b}$ & 3.2 & $76^{x b}$ & $67^{\text {ya }}$ & 11.2 & $33^{x a}$ & $38^{\text {ya }}$ & 8.6 \\
\hline $\begin{array}{c}\text { tarde } \\
\text { 15:00 a 19:00 }\end{array}$ & $159^{\times b}$ & $127^{\text {ya }}$ & 9.3 & $2^{x c}$ & $12^{y c}$ & 4.6 & $27^{\mathrm{xc}}$ & $68^{\text {ya }}$ & 11.2 & $44^{\mathrm{xb}}$ & $41^{\text {ya }}$ & 1.1 \\
\hline ES & 9.4 & 7.2 & & 5.5 & 5.1 & & 7.9 & 6.2 & & 3.5 & 2.7 & \\
\hline $\begin{array}{l}\text { Tiempo total } \\
\text { diurno }\end{array}$ & $293^{x}$ & $356^{y}$ & 12.3 & $71^{x}$ & $75^{x}$ & 4.2 & $224^{x}$ & $191^{y}$ & 11.1 & & & \\
\hline
\end{tabular}

${ }^{1}$ ES. Error estandad

a,b, Entre variables de una columna. Valores con diferente letra presentan diferencias significativas $(\mathrm{P}<0.05)$

$x, y, z-E n t r e$ variables de una fila. Valores con diferente letra presentan diferencias significativas $(P<0.05)$ 
Tabla 3. Tiempos de pastoreo, rumia y descanso (minutos), y tasa de bocado (bocados/min en cada momento del día) de vaquillonas para carne pastoreando franjas diarias en primavera, con asignación de forraje vespertina (AFV) y matutina (AFM)

\begin{tabular}{|c|c|c|c|c|c|c|c|c|c|c|c|c|}
\hline Variable & \multicolumn{3}{|c|}{ Tiempo de pastoreo } & \multicolumn{3}{|c|}{ Tiempo de rumia } & \multicolumn{3}{|c|}{ Tiempo de descanso } & \multicolumn{3}{|c|}{ Tasa de bocado } \\
\hline Tratamiento & AFV & AFM & $\mathrm{ES}^{1}$ & AFV & AFM & ES & AFV & AFM & ES & AFV & AFM & ES \\
\hline $\begin{array}{c}\text { mañana } \\
\text { 07:00 a 11:00 }\end{array}$ & $80^{\mathrm{xa}}$ & $119^{\text {ya }}$ & 13.31 & $84^{x a}$ & $44^{\mathrm{ya}}$ & 7.82 & $95^{\mathrm{xa}}$ & $75^{\mathrm{ya}}$ & 7.8 & $26.4^{x a}$ & $34.5^{\text {ya }}$ & 1.9 \\
\hline $\begin{array}{c}\text { mediodía } \\
\text { 11:00 a 15:00 }\end{array}$ & $57^{\times b}$ & $80^{y b}$ & 8.3 & $63^{x b}$ & $76^{y b}$ & 3.2 & $108^{\times b}$ & $76^{\text {yc }}$ & 12.4 & $32.7^{x b}$ & $30.3^{x b}$ & 2.1 \\
\hline $\begin{array}{c}\text { tarde } \\
15: 00 \text { a } 19: 00\end{array}$ & $140^{\mathrm{xc}}$ & $132^{x c}$ & 15.2 & $18^{\mathrm{xc}}$ & $31^{\mathrm{yc}}$ & 6.54 & $50^{\mathrm{xc}}$ & $62^{\mathrm{yb}}$ & 4.1 & $41^{x c}$ & $38.5^{\mathrm{xc}}$ & 1.5 \\
\hline ES & 9.4 & 7.2 & & 5.5 & 5.5 & & 7.9 & 7.9 & & 2.7 & 2.7 & \\
\hline $\begin{array}{c}\text { Tiempo total } \\
\text { diurno }\end{array}$ & $277^{x}$ & $331^{y}$ & 15.2 & $166^{\mathrm{x}}$ & $151^{x}$ & 8.5 & $253^{x}$ & $213^{y}$ & 13.0 & & & \\
\hline
\end{tabular}

${ }^{1}$ ES. Error estandad

a,b, Entre variables de una columna. Valores con diferente letra presentan diferencias significativas $(P<0.05)$

$x, y, z-E n t r e$ variables de una fila. Valores con diferente letra presentan diferencias significativas $(P<0.05)$

Orr et al. (2001) reportan que vacas con asignación de forraje vespertina tienen menor tasa de consumo en la mañana siguiente, comparadas con aquellas vacas que se le ofrece la nueva asignación esa misma mañana (19 vs. 41 g de MS Imin). La tasa de consumo, en la tarde siguiente se revierte siendo mayor para los animales con asignación vespertina comparados con los de asignación matutina (55 vs. $31 \mathrm{~g}$ de MS/min). Estos resultados sugieren que el momento de asignación del forraje no sólo modifica la frecuencia y distribución de los EP, sino también la intensidad del pastoreo, ya que la tasa de consumo al atardecer ha sido mayor. 
Mc Gilloway et al. (2001) evaluaron la relación entre la reducción de la altura de la pastura en un pastoreo rotativo y la tasa de consumo en el corto plazo, y concluyeron que el factor determinante en el control de la tasa de consumo, a medida que la superficie es progresivamente pastoreada, es la altura de la pastura. Pero con una reducción muy importante de la altura, la densidad de macollos de la pastura también influye en la masa de bocado (Mc Gilloway et al., 2001). Barret et al. (2001), evaluaron los patrones de consumo de forraje, tasa y masa de bocado de vacas lecheras en pastoreos rotativos a medida que la altura de la pastura disminuía, y encontraron que las vacas pastoreando a lo largo del día en pasturas que se agotaban progresivamente presentaban una disminución lineal de la masa de bocado, aún cuando la tasa de consumo era similar, comparadas con vacas pastoreando recursos sin defoliación previa, independientemente del momento del día. En nuestro caso, los animales del tratamiento AFV pastoreaban a la mañana una pastura con un incontrastable grado de defoliación, y esto debería conducir a reducir la tasa de consumo en ese momento, lo cual parece ser compensado a la tarde y/o durante la noche determinando un consumo de MS similar entre los tratamientos. 
Figura 5: Patrón de pastoreo de vaquillonas para carne pastoreando franjas diarias en invierno, con asignación de forraje vespertina (AFV; 15:00 hs) o matutina (AFM; 07:00 hs)

Vaquill.

AFV

1

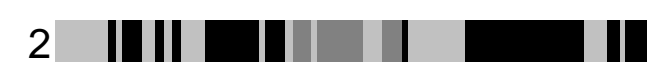

3|| $\mathbf{|}||||||||||$

4

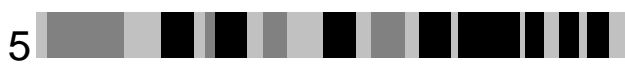

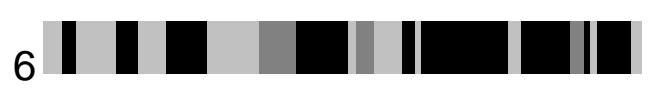

$7 \square$ II

\section{8}

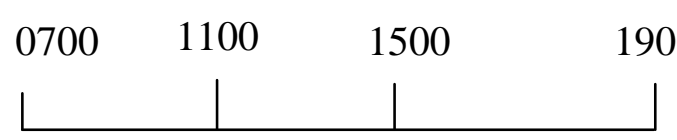

Momento del día

Actividad:

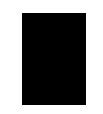

Pastoreo
AFM
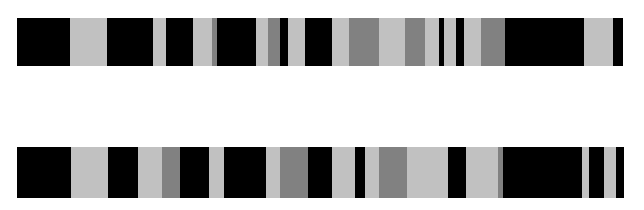

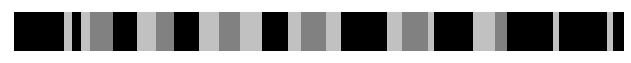
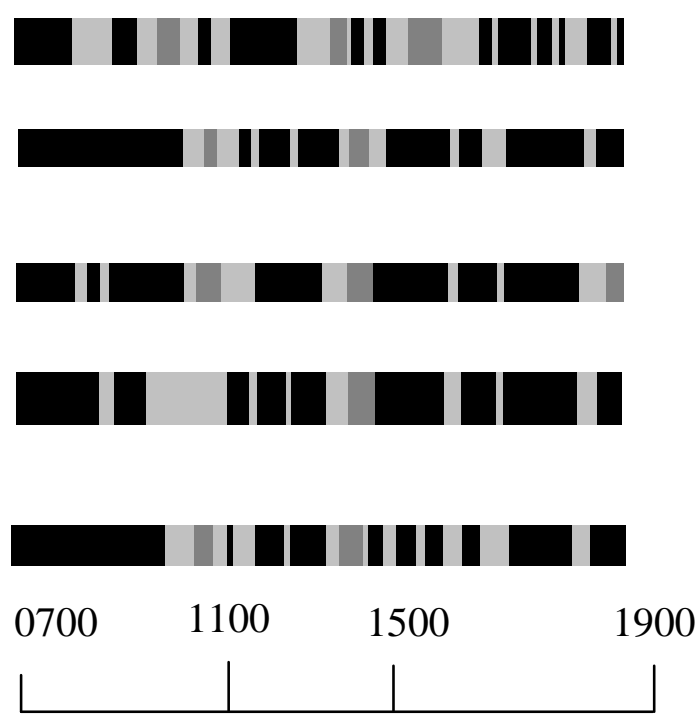

Momento del día

Rumia

Descanso 
Figura 6: Patrón de pastoreo de vaquillonas para carne pastoreando franjas diarias en primavera, con asignación de forraje vespertina (AFV; 15:00 hs) o matutina (AFM; 07:00 hs)

Vaquill.

1

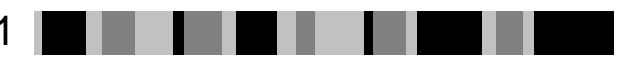

2

. 3

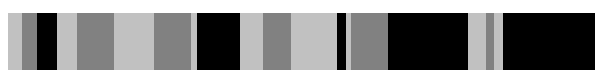

4

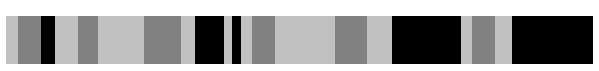

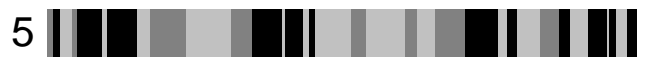

6

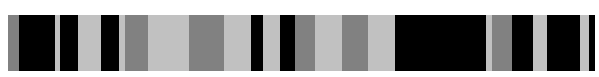

${ }^{7}$ |l||||||| || || ||

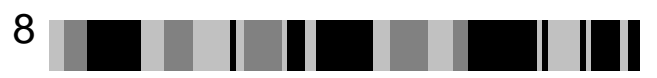

0700

1500

1900

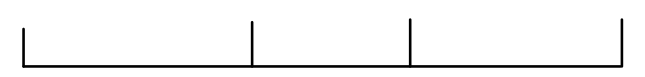

Momento del día
AFM
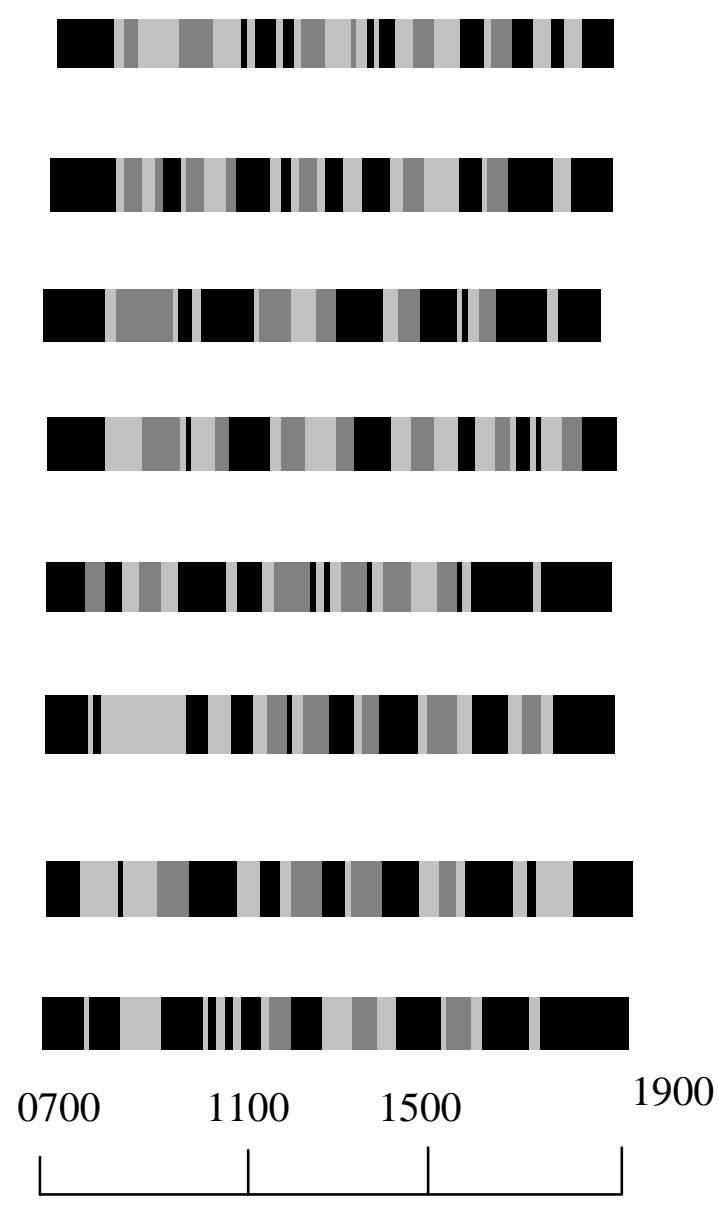

Momento del día

Actividad:

Pastoreo

Rumia

Descanso 


\subsection{EXPERIMENTO 2}

\section{Calidad de forraje}

La disponibilidad, y la altura promedio del forraje no fueron diferentes entre los tratamientos $(P>0.05)$, con valores de $2349 \pm 412 \mathrm{~kg}$ de MS/ha y $23.97 \pm 0.72$ cm respectivamente. Estas características del recurso más la asignación diaria de forraje estipulada (6 \% del PV en MS) implica que en el presente experimento las vaquillonas pastorearon sin limitantes ingestivas (Combellas \& Hodgson, 1979)

La DIVMS aumentó $4.2 \%(\mathrm{P}<0.05)$ a lo largo del día (Tabla 4) La FDN disminuyó 20.54 \% y los CNES aumentaron $33.5 \%$ desde el amanecer hasta el atardecer $(\mathrm{P}<0.05)$. La concentración proteica no mostró variaciones a lo largo del día (Tabla 1). Los valores de Energía Metabolizable (EM= $3.608 \times$ DIVMS) se incrementaron 0.1 Mcal / kg MS desde las 7:00 hs hasta las 17:00 hs. Estos resultados corroboran la explicación de que la mayor variación diaria en el valor nutritivo es atribuible a un incremento de los fotosintatos, que conlleva a una dilución de porcentaje de FDN (Delagarde et al., 2000). Considerando el aumento diario de la concentración de CNES y su potencial fermentación total en el rumen (Van Vuuren, 1993) las pérdidas de $\mathrm{N}$ se verían reducidas y mayores niveles de nutrientes glucogénicos y aminogénicos serían esperables durante la SP de la tarde. 
Tabla 4. Variación de la composición química del forraje (\% de MS) durante las horas del día en una promoción de raigrás, consumida por vaquillonas en un pastoreo en franjas diarias ${ }^{1}$

\begin{tabular}{ccccc}
\hline Variable & DIVMS $^{2}$ & FDN & PB & CNES $^{3}$ \\
\hline Hora del día & & & & \\
700 & $75.56^{\mathrm{a}}$ & $54.86^{\mathrm{a}}$ & 16.73 & $12.0^{\mathrm{a}}$ \\
1300 & $76.5^{\mathrm{ab}}$ & $48.06^{\mathrm{b}}$ & 15.64 & $14.76^{\mathrm{b}}$ \\
1700 & $78.72^{\mathrm{b}}$ & $45.51^{\mathrm{b}}$ & 16.43 & $16.02^{\mathrm{c}}$ \\
ES & 1.93 & 5.05 & 3.78 & 1.09 \\
\hline
\end{tabular}

${ }^{1}$ Los valores son los promedios de tres fechas de muestreo en cada estación, confeccionando muestras compuestas en cada horario a través del seguimiento de 4 animales.

${ }^{2}$ DIVMS. Digestibilidad in vitro de la materia seca

${ }^{3}$ CNES Carbohidratos no estructurales

a,b,c-Entre valores de una columna. Valores con diferente letra presentan diferencias significativas $(p<0.05)$

\section{Consumo y performance productiva}

En el presente experimento, el período de ayuno durante la mañana no afectó el ADPV (AY: 0.7 y SINAY: 0.62 kg/día; P = 0.88, ES = 0.11), ni los cambios en la NCC (AY: 0.012 y SINAY: 0.014 puntos; $P=0.24$, ES $=0.77$ ), ni los consumos de MS estimados (AY: 4.69 y SINAY: $4.17 \mathrm{~kg} / \mathrm{día}$; $\mathrm{P}=0.36, \mathrm{ES}=0.19$ ). Los resultados de las mediciones de consumo son similares a los obtenidos en el Experimento 1. El hecho de no haber encontrado diferencias en el consumo de MS en el presente experimento, sostiene los resultados encontrados en ovejas por Iason et al. (1999), quienes afirman que pese a reducciones en el tiempo disponible para pastoreo debido a períodos de ayuno, los animales pueden mantener el consumo mediante cambios en el comportamiento ingestivo. En este estudio las 
vaquillonas del tratamiento $A Y$ tuvieron una reducción de 8 hs en el tiempo de pastoreo. El efecto de compensar el tiempo perdido, fue además observado por Gregorini et al. (2007a) quien no encontró diferencias en el consumo diario de MS en vaquillonas pastoreando sin ayuno o con un período de ayuno de 20 hs y sesiones de pastoreo de 4 hs.

El pastoreo en el tratamiento AY fue concentrado en la tarde (14:30 a 18:30 hs), cuando la pastura tuvo el mayor valor nutritivo (Tabla 4). Basado en la composición química del forraje, en la DIVMS y en la similitud en las estimaciones de consumo diario de MS, la cosecha de nutrientes y energía de las vaquillonas sometidas al tratamiento AY fue teóricamente mayor. La pregunta es: ¿Por qué $A Y$ no incrementó la performance productiva? Una respuesta podría ser que la población de microflora ruminal, en estos animales, no fue suficiente para procesar una alta tasa de consumo de nutrientes. Después de una noche, en la que se produce abundante rumia, la población microbiana es menor a la mañana (Gibb, M. J. ${ }^{1}$ Com pers.) Además, durante la mañana en AY los animales solo rumian y digieren, compensando incluso mayor llenado ruminal. El ayuno previo incrementa la masa de bocado del ganado en pastoreo (Chacon \& Stobbs, 1977; Patterson et al., 1998; Gregorini et al., 2007a). Laca et al. (1994) encontraron una relación lineal negativa entre cantidad de movimientos mandibulares de masticación por bocado y masa de bocado, lo que está indicando que el grado de fragmentación del forraje ingerido decrece con el incremento de la masa de bocado. La masticación acondiciona el forraje para su digestión, destruyendo capas protectoras (pared celular, cutina) exponiendo el contenido celular a las enzimas digestivas (Pond et al., 1984; Boudon \& Peyroud, 2001). En promedio el $65 \%$ del contenido de agua

\footnotetext{
${ }^{1}$ Gibb, M. J. Inst. of Grassland and Environment Res. North Wyke, Devon, UK
} 
de la planta es liberado con la masticación (Hogan et al., 1987), presumiblemente el $50 \%$ de los carbohidratos solubles y el $30 \%$ del nitrógeno intracelular (Mangan et al., 1976; Boudon \& Peyroud, 2001). Esta hipotética reducción en la masticación aumenta el problema de la pequeña población microbiana recibiendo un alto consumo de nutrientes. Consecuentemente, cambios en los patrones de fermentación ruminal en AY no serían lo suficientemente grandes como para alterar significativamente el aporte de nutrientes a pesar de las diferencias en la calidad del forraje potencialmente consumido. El aporte de energía pudo haber sido mayor en AY, pero probablemente no fue utilizado eficientemente por una falta de sincronización con la población microbiana. Este fenómeno puede ser explicado por los resultados presentados por Gregorini et al. (2007a), quien encontró un aporte similar de nutrientes (AGV totales y proteína microbiana a nivel duodenal) para vaquillonas de biotipo carnicero, comparando AY y SINAY (en un lapso de 20 horas de ayuno)

\section{Comportamiento ingestivo}

El análisis de las mediciones de comportamiento (Tablas 5 y 6), muestran que en el atardecer el tiempo de pastoreo tiende a incrementarse $(20 \mathrm{~min}$.; $\mathrm{P}=$ 0.10) y el tiempo de descanso se reduce (16 min.; $P=0.09)$. En el tratamiento $A Y$, el tiempo de rumia fue 0 min. y la tasa de bocado se incrementó (AY: 62 vs. SINAY: 54 bocados / min.; $\mathrm{P}=0.01$ ). Observando los tiempos dedicados a cada actividad, el ayuno matutino produce una reducción en el tiempo diurno total de pastoreo en 81 minutos $(P=0.01)$, lo cual está reflejado además en la tendencia $(P=0.06)$ a pasar más tiempo en descanso durante la mañana (51 min.). El tiempo diurno dedicado a la rumia no fue afectado $(P>0.05)$. La frecuencia y distribución 
(promedio de todas las vaquillonas estudiadas) de las actividades de comportamiento analizadas se muestra en la Figura 7. Estos resultados, junto con las estimaciones de consumo descriptas en el estudio de performance productiva, demuestran como en otros trabajos (Dougherty et al., 1989; Chilibroste et al., 2004; Gregorini et al., 2006) los efectos de la hambruna en el comportamiento ingestivo y en su patrón. No obstante, parece ser que este es un efecto de corta duración, alcanzando solo el primer EP posterior al ayuno. Este fenómeno es comprobado por Gregorini et al. (2007a), quien encontró que después de un ayuno de 20 hs los animales dejaban de pastorear luego de terminada la sesión de pastoreo de 4 hs. En el presente experimento, como se señaló arriba los animales sometidos a ayuno, tendieron a pastorear más tiempo durante el periodo observado (20 min.; P $=0.10)$. La falta de significancia probablemente indique que el nivel de ayuno no fue suficiente para modificar de modo importante el tiempo de pastoreo vespertino, aunque esto no quiere decir que el ayuno no haya tenido ningún efecto sobre él. El ayuno puede haber tenido efecto en la frecuencia y distribución de los EP en la sesión de pastoreo vespertina, como se observa en la Figura 7. Esta distribución concuerda con la descripta por Greenwood \& Dement (1988) quienes observaron que novillos ayunados durante 36 hs. pastorearon mas tiempo en los EP iniciales que animales no ayunados. Patterson et al. (1998), encontraron que la duración del efecto del ayuno depende de su nivel de intensidad, explicando la ausencia de diferencias significativas en el tiempo de pastoreo vespertino entre los tratamientos. De acuerdo con Jung \& Koong (1985), el estímulo más fuerte en la respuesta al ayuno debería ser el llenado ruminal. La percepción de condiciones ruminales a través de señales físicas negativas, condicionan la respuesta inmediata, probablemente en el tiempo que dura una sesión de pastoreo (Gregorini et al., 
2006), lo que explica también el corto efecto de los efectos del ayuno. Estos conceptos no solo se explican con los resultados obtenidos por Patterson et al. (1998), sino que también por Gregorini et al. (2006), quienes muestran que el nivel de llenado ruminal está relacionado negativa y linealmente al tiempo dedicado a comer y positivamente al tiempo de búsqueda.

Dentro de este experimento Wade et al. (2006), condujeron un ensayo, enfocado hacia el efecto del ayuno matutino en el comportamiento del animal en relación a las estaciones de pastoreo. Las vaquillonas mostraron diferencias significativas entre tratamientos, realizando en AY 2,8 bocados mas por estación de pastoreo (AY, 11.5 vs. SINAY, 8.7; $P=0.02$ ). Resultados similares fueron reportados por Gregorini et al. (2006). A medida que el llenado ruminal se incrementaba, el número de bocados dados por estación de pastoreo disminuía. Esto indica que el efecto del hambreado también puede inducir diferencias en las decisiones de pastoreo a escala más pequeña. No obstante, en el presente experimento los tratamientos no solo hicieron a los animales distribuir su tiempo de pastoreo en forma diferente, sino que cambiaron también su distribución espacial. Esto sugiere que la reacción de los animales a la percepción de un mismo recurso fue definitivamente afectada por el ayuno.

En general la tasa de bocado se va incrementando a lo largo del día, siendo máxima al atardecer (Gibb et al., 1998). Varios estudios (Patterson et al., 1998; Iason et al., 1999; Realini et al., 1999) ya han demostrado como la tasa de bocado es afectada por el estado de la pastura o por el estado interno del animal. No obstante, sólo los estudios de Orr et al., (2001) y los resultados obtenidos en el Experimento I, muestran cómo el patrón natural de la tasa de bocado es modificado cuando se hacen coincidir los diferentes estados diarios del animal y de la planta, 
encontrando un incremento $(P<0.05)$ en dicha tasa al atardecer, cuando vacas lecheras y vaquillonas para carne, respectivamente, fueron conducidas a una nueva parcela diaria a la tarde. En el presente estudio (Experimento 2) mediante un ayuno matutino se logró incrementar la tasa de bocado en 8 bocados/ min. (Tabla 6, $\mathrm{P}<0.05)$. El patrón diario de la tasa de bocado aparece como posible de modificar mediante diferentes estímulos internos y externos

Este experimento combinó los dos tipos de efectos, incrementando el estímulo que motivó el comportamiento ingestivo, resultando en una mayor tasa de bocado. Teóricamente, las vaquillonas en el tratamiento AY consumieron la misma cantidad de forraje, en dos tercios del tiempo, que las vaquillonas del tratamiento SINAY. El aumento de la tasa de bocado puede no haber sido el único mecanismo de compensación, y otros cambios, como la masa de bocado, pueden haber actuado. Esto es apoyado por los resultados de Greenwood \& Dement (1988), Patterson et al. (1998), Gregorini et al. (2007a) y Gregorini et al. (2006).

Tabla 5. Tiempo total diurno de pastoreo, rumia y descanso de vaquillonas para carne, conducidas en franjas diarias con asignación vespertina, con (AY) o sin ayuno (SINAY) matutino de 8 hs.

\begin{tabular}{|c|c|c|c|c|}
\hline \multirow{2}{*}{ Variable } & \multicolumn{2}{|c|}{ Tratamiento } & \multirow{2}{*}{ ES } & \multirow{2}{*}{ valorP } \\
\hline & AY & SINAY & & \\
\hline $\mathrm{TP}$ (min) & 201 & 282 & 21.16 & 0.01 \\
\hline TR (min) & 68.75 & 54.25 & 8.95 & 0.27 \\
\hline TD (min) & 347 & 296 & 19.34 & 0.06 \\
\hline
\end{tabular}

\footnotetext{
${ }^{1} \mathrm{TP}$, Tiempo de pastoreo; TR, Tiempo de rumia; TD, Tiempo de descanso.
} 
Tabla 6. Tasa de bocado, tiempo de pastoreo, rumia y descanso durante el evento de pastoreo de la tarde de vaquillonas para carne, conducidas en franjas diarias con asignación vespertina, con (AY) o sin ayuno (SINAY) matutino de $8 \mathrm{hs}$.

\begin{tabular}{|c|c|c|c|c|}
\hline \multirow{2}{*}{ Variable } & \multicolumn{2}{|c|}{ Tratamiento } & \multirow{2}{*}{ ES } & \multirow{2}{*}{ valorP } \\
\hline & AY & SINAY & & \\
\hline $\mathrm{TP}$ (min) & 201 & 181 & 8.54 & 0.10 \\
\hline TR (min) & 0 & 0 & - & - \\
\hline $\mathrm{TD}$ (min) & 42 & 58 & 6.11 & 0.09 \\
\hline TB (bocados/min.) & 62 & 54 & 1.71 & 0.01 \\
\hline
\end{tabular}

${ }^{1} \mathrm{TP}$, Tiempo de pastoreo; TR, Tiempo de rumia; TD, Tiempo de descanso; TB, Tasa de bocado.

Figura 7: Frecuencia y distribución de los eventos de pastoreo, rumia y descanso de vaquillonas para carne bajo un pastoreo en franjas diarias con asignación vespertina, con ayuno (AY) o sin ayuno (SINAY) matutino de 8 hs.
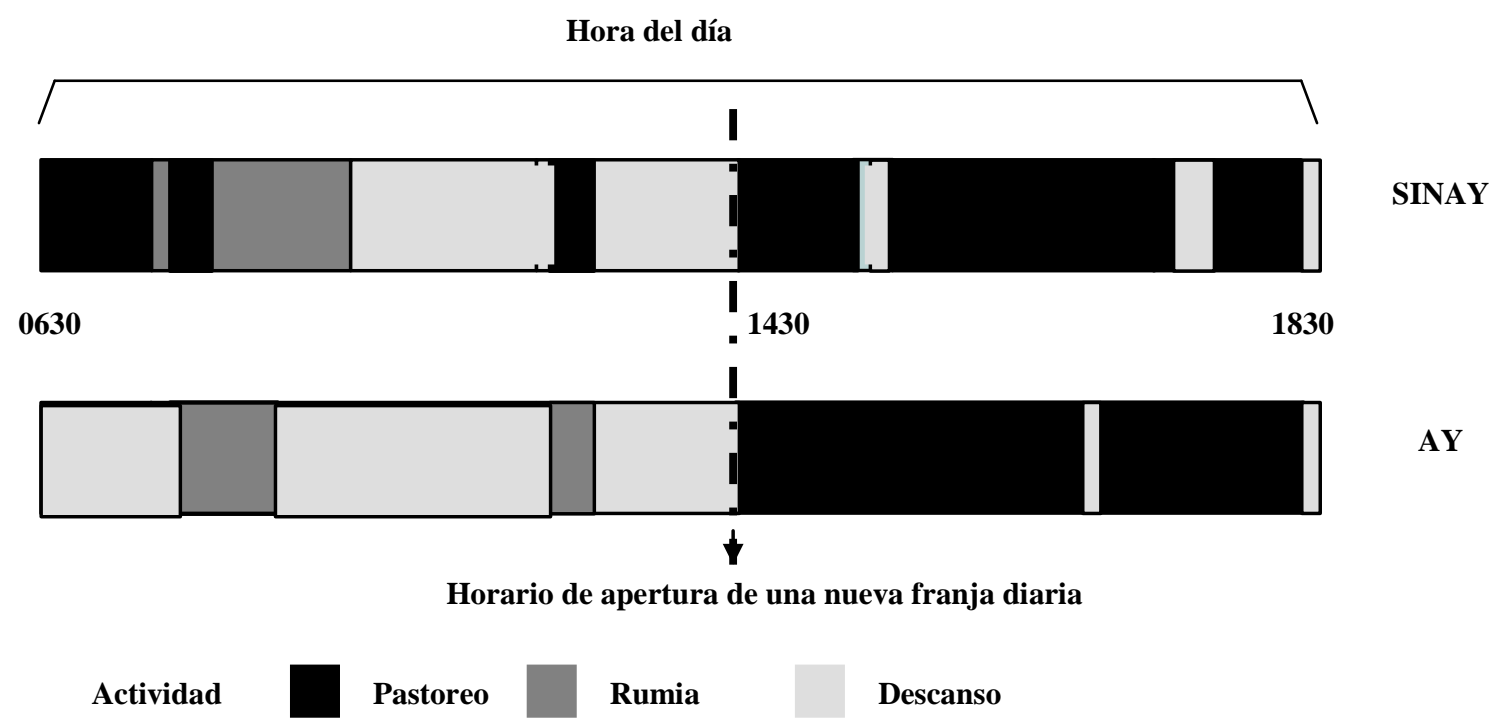

Período de ayuno para el tratamiento AY: de 6:30 a 14:30 


\section{DISCUSIÓN GENERAL}

Resulta interesante desarrollar en esta sección algunos aspectos que engloban y exceden a los dos experimentos realizados en este trabajo, en relación a la validéz de la metodología utilizada y a la trascendencia de los resultados obtenidos.

Desde el análisis de la metodología empleada, el uso del animal como unidad experimental ha sido simultáneamente cuestionado y valorado en la literatura científica (Rook, 2004). La limitación estadística que surge de realizar mediciones repetidas en el tiempo sobre el mismo animal se supera mediante los métodos estadísticos que contemplan esa situación y que han sido utilizados en este trabajo (PROC MIXED de SAS, SAS Inst. inc., Cary. NC). Otros aspectos que pueden restar independencia a las observaciones son las interacciones de facilitación social o competencia derivadas del manejo conjunto de los animales, que no se resuelven con la separación espacial individual de los mismos porque esta situación modifica el comportamiento normal.

Con relación a las técnicas desarrolladas y actualmente utilizadas para medir el consumo de forrajes de animales en pastoreo, hemos utilizado la diferencia entre el forraje disponible antes de la introducción de los animales y el residual después que estos salen de la pastura. La selección de esta opción se basó en la disponibilidad de recursos y los objetivos de investigación. Como desventajas de esta técnica, podemos mencionar que depende de la corrección en las estimaciones de la masa de forraje y que no contempla la acumulación de material vegetal durante el periodo de pastoreo, por lo cual sólo es útil para sistemas con periodos cortos y presiones altas de pastoreo (Meijis et al., 1982), como es el caso de nuestros ensayos. Otro inconveniente es que no provee datos individuales del 
consumo, excepto que los animales sean manejados individualmente. Nuestro ensayo se llevo a cabo con grupos de animales, permitiendo ello obtener un comportamiento normal en el patrón de pastoreo, ya que los animales deben pastar en grupo para expresar su "comportamiento de hato" (Penning et al., 1993; Rook et al., 1996).

Otro aspecto a mencionar es que en este ensayo se asumió que el comportamiento observado durante las horas de luz explica lo sucedido en el período de 24 h y se minimizó el pastoreo que podría haber ocurrido durante la noche. Al respecto, Erlinger et al. (1990), hallaron que vacas lecheras en una pradera anual en Gran Bretaña pastorearon 20 a 30\% del tiempo total de pastoreo en la noche, destacando que el largo del día influye notoriamente en el tiempo de pastoreo nocturno. Albright (1993) señaló que en promedio, 85\% del tiempo total de pastoreo ocurre durante el día y solamente $15 \%$ durante la noche. Sin embargo, otros autores mencionan que el momento de asignación de una franja diaria de pastoreo (mañana vs. tarde) influye sobre la proporción del pastoreo nocturno y este puede resultar de hasta un $43 \%$ en el periodo que va de 18:30 a 8:30 hs (Nadin et al., 2008).

Los resultados de este trabajo corroboran las ventajas que genera la utilización de lo que fue denominado "tecnología PM" por Mayland et al. (2005). Esta expresión fue sustentada con el simple cálculo que henificar forraje a la tarde en lugar de la mañana incrementaría en un $5 \%$ el valor alimenticio de los henos de alfalfa, lo cual significaría una ganancia extra de 300 millones de dólares en la producción de leche de USA. Los resultados de esta tesis confirman, además, que esta ventaja se puede capitalizar también en pastoreo cuando se usa pastoreo en franjas diarias con asignación vespertina, ya que un simple cambio en el momento 
del día en la asignación de la pastura, en la tarde en lugar de temprano en la mañana, altera la duración e intensidad de los eventos de pastoreo y la conexión entre ellos en una distribución temporal. El pastoreo al atardecer es más prolongado e intenso, cuando el forraje tiene mayor valor nutritivo.

La utilización de este tipo de tecnología de proceso requeriría mayor investigación básica en temas relativos a las respuestas del metabolismo general y hormonal, y los cambios en el comportamiento ingestivo, provocados por variaciones del llenado ruminal a corto plazo. El rumen recibe forraje consumido en una secuencia discontinua definida por el patrón diario de pastoreo (Gregorini et al., 2006). La cantidad total de forraje dentro del rumen, referida como "llenado ruminal", y la tasa a la que ese forraje es compactado y reducido en tamaño durante su aprehensión, aumenta progresivamente desde la mañana hasta el atardecer. Existe evidencia de que el llenado ruminal no es completado al final de los eventos de pastoreo de la mañana y del mediodía pero si en el de la tarde (Taweel et al., 2005; Gregorini et al., 2007) y que ese nivel de llenado ruminal tiene una fuerte relación con el comportamiento ingestivo a nivel evento de pastoreo (Gregorini et al., 2007; Gregorini et al., 2009) como se señaló en 2.3.4.

Chilibroste et al. (2007) argumentan que cuando los animales consumen forraje fresco, no muestran dificultades para colocar un gran volumen de forraje en el rumen, pero pueden fallar en acomodarlo adecuadamente y que esto puede ocurrir fundamentalmente durante el evento de pastoreo de la mañana. Durante una comida algunas señales de saciedad provienen de receptores mecánicos situados en las paredes del rumen (Gill et al., 1998). Por lo tanto fracasar en acomodar el forraje consumido a lo largo del evento de pastoreo, puede disparar una estimulación sobre estos receptores, incrementando señales de ralentar el 
proceso, promoviendo la selectividad y llevando finalmente a detener el pastoreo. Esto es más factible que ocurra durante el primer turno de pastoreo, posterior al natural período de ayuno, la noche.

La incertidumbre es significativa en torno al conocimiento sobre las tasas de pasaje y los factores que las afectan. Es necesario continuar el estudio de cambios en estas tasas en función de la hora del día, así como en relación a la disponibilidad y calidad del forraje. Las variaciones diurnas en el contenido de materia seca y nutrientes, con sus efectos sobre el consumo, aportarán datos y evidencias para explicar cambios en el patrón de consumo. Sobre todo en cuanto estos estudios, sirvan también para explicar las variaciones diurnas en la dieta como resultado de la selectividad del animal.

La aplicación al pastoreo de la llamada "Tecnología PM", se sustenta en que la asignación vespertina hace que el evento de pastoreo de la tarde sea más largo e intenso, cuando el forraje tiene el mayor valor nutritivo. También en que períodos cortos de ayuno previos a la asignación vespertina acentúan ese cambio en el comportamiento, generando eventos de pastoreo aún más largos e intensos durante las horas del atardecer. Derivado de estas respuestas, es importante detenerse en el hecho que se puede obtener el mismo consumo de nutrientes y nivel de productividad en sesiones de pastoreo más cortas.

Esto nos conduce a pensar en algunas ventajas adicionales como pueden ser las producidas por la reducción del pisoteo de los animales. Este reduce la producción de las pasturas, principalmente por daños físicos a las plantas, y también por compactación del suelo con la consiguiente reducción en la fertilidad y en la penetración de agua en el perfil (Edmond, 1963). Las plantas en suelos compactados desarrollan raíces más superficiales, y se vuelven más susceptibles a 
deficiencias de agua. Consecuentemente, si los ayunos previos a las asignaciones vespertinas de franjas diarias permiten a los productores reducir el tiempo de permanencia de los animales sobre las pasturas, la producción futura de esas pasturas podría incrementarse debido al menor daño por pisoteo, pero debería tenerse en consideración un importante traslado de nutrientes hacia los sitios de ayuno. Esta tecnología debe estar acompañada por sistemas de recuperación de nutrientes en los sitios de ayuno, que permitan manejar las excretas para su devolución controlada hacia las pasturas. Se evitaría asi, además, el impacto ambiental generado por las deposiciones concentradas de $\mathrm{N}$ durante el pastoreo.

La investigación sobre los factores involucrados en los procesos de ingestión y digestión en el pastoreo, es esencial no solo para comprender los mecanismos determinantes del comportamiento ingestivo, el consumo voluntario, y la eficiencia intrínseca de aprovechamiento de los nutrientes en los rumiantes, sino además para diseñar estrategias de pastoreo y suplementación que puedan contribuir a superar el gran desafío que enfrentan los productores de carne en sistemas pastoriles: incrementar la cosecha de nutrientes del pasto. 


\section{CONCLUSIONES}

De acuerdo con los resultados obtenidos se puede aceptar la hipótesis de trabajo propuesta.

- La elección del momento del día en la asignación de la pastura permitió manipular el patrón diario de pastoreo. La asignación vespertina hizo que el evento de pastoreo de la tarde sea más largo e intenso.

- Períodos cortos de ayuno previos a la asignación vespertina acentuaron ese cambio en el comportamiento, generando eventos de pastoreo aún más largos e intensos durante las horas del atardecer, lográndose el mismo consumo voluntario de forraje en menos tiempo diurno de pastoreo.

- Ese incremento en la actividad de pastoreo generado por la asignación vespertina y/o el ayuno matutino se desarrolló durante el momento del día en que el forraje tiene el mayor valor nutritivo

- Consecuentemente, se logró afectar positivamente el aumento diario de peso vivo de vaquillonas de biotipo carnicero en crecimiento. 


\section{BIBLIOGRAFÍA}

Allden, W. G. \& Whittaker, I. A. 1970. The determinants of herbage intake by grazing sheep: the interrelationship of factors influencing herbage intake \& availability. Aust. J. Agric. Res, 21:755-766.

Albright, J. 1993. Feeding behaviour of dairy cattle. J. Dairy Sc. 76:485-498.

Arnold, G. W. \& Dudzinski, M. L. 1978. Ethology of free-ranging domestic animals. Elsevier Sci. Publ. Comp. New York. 198 pp.

Baile, C. A. \& Forbes, J. M. 1974. Control of feed intake and regulation of energy balance in ruminants. Phis. Rev. 54: 160-214

Bailey, D. W. Gross, J. E. Laca, L. R. Rittenhouse, M. B. Coughenour, D.M. Swift, R. M. \& Sims, P. L. 1996. Mechanism that result in large herbivore grazing distribution patterns. J. Range. Man. 49:386-400.

Barret, P. D. Laidlaw, A. S. Mayne, C. S. \& Chistie, H. 2001. Pattern of herbage intake rate and bite dimensions of rotationally grazed cows as sward height declines. Grass \& For. Sci. 56:362-373.

Barthram, G. T. 1986. Experimental techniques: The HFRO sward stick. Pages 29, 30 in Biennial report, 1984-85. M. M. Alcok, ed. Hill Farm. Res. Org. Penicuik, Midlothian, U.K.

Beever, D. E. \& Siddons. R. C. 1986. Digestion and Metabolism in the grazing ruminant. En: P. Milligan, W. L. Grovum and A. Dobson (Eds). Control of Digestion and Metab. in Ruminants. P. 479. Acad. Press, New York.

Bines, J. 1971. Metabolic and physical control of food intake in ruminants. Proc. Of the Nutrition Soc. 30:116-122 
Boudon, A. \& Peyraud, J. L. 2001. Release of intracellular constituents from fresh ryegrass (Lollium perenne L.) during ingestive mastication in dairy cows: effect of intracellular constituent, season and stage maturity. Anim. Feed Sci. Tech. 93: 229245

Bremner, J. M. \& Mulvaney, C. S. 1982. Nitrogen total. Pages 595-624 in L. R. H. Miller and K. R. Kenny. Methods of Soil Analysis. Part 2. Chemical and Microbiological Properties. $2^{\text {nd }}$ ed. Series Agronomy No 9. Am. Soc. Agron. Soil Soc. Am., Madison, WI.

Burns, J. C. Mayland, H. F. \& Fisher, D. S. 2005. Dry matter intake and digestion of alfalfa harvested at sunset and sunrise. J. Anim. Sci. 83:262-270.

Cabrera Estrada, J. I. Delagarde, R. Faverdin, P. \& Peyraud, J. L. 2004. Dry matter intake and eating rate of grass by dairy cows is restricted by internal, but not external water. An. Feed Sci. and Tech. 114:59-74.

Chacon, E. \& Stobbs, T. H. 1976. Influence of progressive defoliation of grass sward on the eating behaviour of cattle. Aust. J. Agric. Res, 27:709-727.

Chacon, E. \& Stobbs, T. H. 1977. The effect of fasting prior to sampling and diurnal variation on certain aspects of grazing behavior of cattle. Appl. Anim. Ethol. 3:163

Chacon, E. Stobbs, T. H. \& Dale, M. B. 1978. Influence of sward characteristics on grazing behaviour and growth of Hereford steers grazing tropical grass pastures. Aust. J. Agric. Res, 29:89-102.

Champion, R. S. Rutter, S. M. Penning, P. D. \& Rook, A. J. 1994 temporal variation in grazing behavior of sheep and the reliability of sampling periods. Appl. Anim.. Behav. Sci. 42:99-108.

Charles-Edwards, D. A. 1982. Physiological Determinants of Crop Growth. (Academic Press: Sydney). 
Charnov, E. L. Gordon, H. O. \& Hyatt, K. 1976. Ecological implications of resource depression. Am. Nat. 110:247.

Chilibroste, P. Soca, P. \& Mattiauda, D. A. 1999. Effect of the moment and length of the grazing session on: 1 . Milk production and pasture depletion dynamics. In: Proc. $2^{\text {nd }}$ Int. Symp. Grassland Ecophysiol. and Grazing Ecol. pp.292-295.

Chilibroste, P. Soca, P. Mattiauda, D. A. \& Betancour, O. 2004. Incorporation of short-term fasting in grazing and feeding management strategies for cattle: An integrated aproach. In: Proc. $2^{\text {nd }}$ Int. Symp. Grassland Ecophysiol. and Grazing Ecol. J. Pizarro Ed. Curitiva. Parana. Brasil.

Chilibroste, P. M. Gibb, M. J. \& Tamminga, S. 2005. Pasture characteristics and animal performance. In: Quantitative Aspects of Ruminant Digestion and Metabolism (J. France, M. Forbes \& J. Dijkstra, Eds.), CAB International, Wallingford.

Chilibroste, P. Soca, P. Mattiauda, D.A. Bentancur, O. \& Robinson, P.H. 2007. Short term fasting as a tool to design effective grazing strategies for lactating dairy cattle: a review. Aus. J. of Agri. Res., 47, 1075-1084.

Church, R. M. 1989. Theories of timing behavior. In S. B. Klein, \& R. Mowrer (Eds) Contemporary learning theory. Hillsdale, NJ: Erlbaum, pp 41-69.

Ciavarela, T. A. Dove, H. Leury, B.J. \& Simpson, R.J. 2000a. Diet selection by sheep grazing Phalaris aquatica L. Pastures of different water-soluble carbohydrate content. Aust. J. Agric. Res. 51: 757-764.

Ciavarela, T. A. Simpson, R.J. Dove, H. Leury, B.J. \& Sims, I.M. 2000b. Diurnal changes in the concentration of water-soluble carbohydrate in Phalaris aquatica L. Pasture in spring, and the effect on short term shading. Aust J. Agric. Res. 51: 749756.

Collier, G. \& Johnson, D. F. 1990. The time window of feeding. Phys \& Behav, 48, 771-777. 
Combellas, J. \& Hodgson, J. 1979. Herbage intake and milk production by grazing dairy cows. 1.The effect of variations in herbage mass and daily herbage allowance in a short-term trial. Grass \& For. Sci. 34: 209 -214.

Cowan, R. T. 1975. Grazing time \& pattern of grazing of Friesian cows on tropical grass-legume pasture. Aust. J. Exp. Agr. \& An. Hus. 15:32-37.

Cowan, R. T. \& O Grady, P. 1976. Effect of presentation yield of a tropical grasslegume pasture on grazing time \& milk yield Friesian cows. Tropical Grasslands, 10:213-218.

Dalley, D. E. Roche, J. R. Moate, P. J. \& Grainger, C. 2001. More frequent allocation of herbage does not improve the milk production of dairy cows in early lactation. Aust. J. Exp. Agr. 41:593-599.

Delagarde, R. Peyraud, J. L. Delaby, R. \& Faverdin, P. 2000. Vertical distribution of biomass, chemical composition and pepsin-cellulase digestibility in a perennial ryegrass sward: interaction with month and year, re-growth age and time of day. An. Feed Sci. and Tech.84: 49-68

Dougherty, C. T. Bradley, N. W. Cornelius, P. L. \& Lauriault, L. M. 1989. Shortterm fasts and the ingestive behavior of grazing cattle. Grass \& For. Sci. 44:295.

Edmond, D. B. 1963. Effects of Treading Perennial Ryegrass (Lolium perenne L.) anci Withe Clover (Tripholium repens L.) Pastures in Winter and Summerat Two Soil Moisture Leveis. NZ. J. of Agri. Res., 6:265-276.

Elizalde, J.C. \& Santini, F. J. 1992. Factores nutricionales que limitan las ganancias de peso en bovinos en el período otoño-invierno. Boletín Técnico Nro. 104.EEA INTA Balcarce.

Elizalde, J. C. Santini, F. J. \& Pasinato, A. M. 1994. The effect of stage of harvest on the proceses of digestion in cattle fed winter oats indoors. Digestion of organic 
matter, neutral detergent fibre and water soluble carbohidrates. Anim. Feed. Sci. Tchnol. 47: 201-211

Erlinger, L. Tolleson, D. R. \& Brown, C. J. 1990. Comparison of bite size, biting rate and grazing time of beef heifers from herds distinguished by mature size and rate of maturity. J. Anim. Sci. 68:3578-3587.

Fisher, D. S. Mayland, H. F. \& Burns, J. C. 1999. Variation in ruminant preference for tall fescue hays cut at sundown or sunup. J. Anim. Sci. 77:762-768.

Fisher, D. S. Mayland, H. F. \& Burns, J. C. 2002. Variation in ruminant preference for alfalfa hays cut at sunup or sundown. Crop Sci. 42:231-237.

Forbes, J. M. 1995. Voluntary Feed intake and diet selection in farm animals. CAB International, Wallinford.

Forbes, J. M. \& Coleman, S. W. 1987. Herbage intake \& ingestive behaviour of grazing cattle as influenced by variation on sward characteristics. In: Grazing-lands research at the plant-animal interface. Ed. Winrock International, 141-152.

Fulkerson, W. J. Slack, K. \& Lowe, K. F. 1994. Variation in the response of Lolium genotipes to defoliation. Aust. J. Agric. Res. 45, 1309-1317.

Fulkerson, W. J. Slack, K. Henessy, D. W. \& Hough, G. M. 1998. Nutrients in ryegrass (Lollium sp), white clover (Trifolium repens) and kikuyu (Pennisetum clandestinum) pasture in relation to season and stage of regrowth in a subtropical environment. Aust J. Agric. Res. 38: 227-240

Garza, R. Barnes, R. F. Mott, G. O. \& Rhykerd, C. L. 1965. Influence of light intensity, temperature and growing period on the growth, chemical composition and digestibility of culver and tanverde alfalfa seedling. Agron. J. 57:417-420

Gibb, M. J. 1998. Animal grazing/intake terminology and definitions. Pasture ecology and animal intake. Pages 21-37 in M. G. Keane and E. G. O'Riordan Proc. 
Workshop Pasture Ecology Anim. Intake. September, 1996. Occasional Publ. No. 3. Concerted Action, AIR-CT93-0947, Dublin, Ireland.

Gibb, M. J. Huckle, C. A. \& Nuthall, R. 1998. Effect of time of the day on grazing behaviour by lactating dairy cows. Grass \& For. Sci. 53: 41-46.

Gibb, M. J. Huckle, C. A. Nuthall, R. \& Rook, A. J. 1999. The effect of physiological state (lactating or dry) \& sward surface height on grazing behaviour \& intake by dairy cows. Appl. Anim. Behav. Sci. 63:269-287.

Gill, J. L. 1978. Desing and analysis of experiments in the animal and medical sciences. Iowa St. Univ. press. Vol. 2, p 301.

Gill, M. Rook, A. J. \& Thiago, L. R. S. 1998. Factors affecting the voluntary intake of roughages by the dairy cow. p. 262 in Nutrition and Lactation of the Dairy Cow. P.C. Gansworthy, ed. Butterworths, London, UK.

Gillen, R. L. \& Smith, E. L. 1986. Evaluation of the dry-weight rank method for determining species composition in tallgrass prairie. J. Rang. Man. 39:283-285.

Gregorini, P. Tamminga, S. \& Gunter, S.A. 2006. Daily grazing patterns of cattle: a behavioral overview. Prof. An. Sci., 22:201.

Gregorini, P. Gunter, S. A. Masino, C. A. \& Beck, P. A. 2007. Effects of ruminal fill on short-term herbage intake rate and grazing dynamics of beef heifers. Grass and For. Sci. 62: 346-354.

Gregorini, P. Bowman, M. Coblentz, W. Beck, P. A. and Gunter, S. A. 2007a. Effect of herbage depletion on cattle grazing dynamics in wheat pastures. J. An. Sci. 85 (Suppl. 1):105. (Abstr.).

Gregorini, P. Soder, K. J. \& Sanderson, M. A. 2008. Case Study: A Snapshot in Time of Fatty Acids Composition of Grass Herbage as Affected by Time of Day. The Prof. An. Sci. 24 (2008):1-6 
Gregorini, P. Soder, K. J. \& Kensinger, R. S. 2009. Effects of rumen fill on shortterm ingestive behavior and circulating concentrations of ghrelin, insulin, and glucose of dairy cows foraging vegetative micro-swards. J. of Dairy Sci. 92(5):2095-2105.

Gregorini, P. Soder, K. J. Sanderson M. A. \& Ziegler, G. R. 2009a. Toughness, particle size and chemical composition of meadow fescue (Festuca pratensis Hud.) herbage as affected by time of day. Anim. Feed Sci. Tech. (2009), vol 10:1016.

Greenwood, G. B. \& Dement, M. W. 1988. The effect of fasting on short-term cattle grazing behavior. Grass \& For. Sci. 43:377.

Griggs, T. C. MacAdam, J. W. Mayland, H. F. \& Burns, J. C. 2005. Nonstructural carbohydrate and digestibility patterns in orchardgrass swards during daily defoliation sequences initiated in evening and morning. Crop Sci. 45:1295-1304.

Grovum, W. L. 1987. A new look at what is controlling food intake. Proc feed Intake Symposium. Exp. St Oklahoma st. Univ. 1-40.

Hancock, J. 1952. Grazing behaviour of identical twins in relation to pasture type, intake \& production of dairy cattle. Proc. of the $6^{\text {th }}$ Inter. Grassland Cong. Pennsylvania, 2:1399-1407.

Hirata, M. T. Iwamoto, W. Otozu, H. \& Kiyota, D. 2002. The effects of recording interval on the estimation of grazing behavior of cattle in a daytime grazing system. Asian-Aust. J. Anim. Sci. 15:745-750.

Hodgson, J. 1982. Ingestive behaviour: En Leaver, J. D. (eds) Herbage intake handbook, pp 113-138.

Hodgson, J. 1990 Grazing Management: Science to Practice. Ed. Longman \& Scientific technical. Essex. UK. 203 pp. 
Hogan, J. P. Kenny, P. A. \& Weston, R. H. 1987. Factor affecting the intake of feed by grazing animals. En: Wheeler, J. L., Pearson, C. J. y Robards, G. E. (Eds.). Temperature pastures: Their Production, Use \& Management. Wool Research Corporation and CSIRO, Melbourne. Australia.

Hudson, R. \& Frank, S. 1987. Foraging ecology of bison in aspen boreal habits. J. Range Man. 40: 71-75.

lason, G. R. Mantecon, A. R. Sim, D. A. Gonzalez, J. Foreman, E. Bermudez, F. F. \& Elston, D. A. 1999. Can grazing sheep compensate for a daily foraging time constraint. J. Anim. Ecol. 68:87.

Illius, A. W. \& Gordon, I. J. 1999. The physiological ecology of mammalian herbivore. Pages $71-96$. In Proc. $5^{\text {th }}$ Symp. On the nutrition of hebivores. Nutr. Ecol. Of Herb. San Antonio. TX.

Jones, B. \& Kenward, M. G. 1989. Desing and analysis of Cross-Over trials. Chapman and Hall, London.

Jung, H. G. \& Koong, L. J. 1985. Effects of hunger station on diet quality by grazing sheep. J. Range Man. 38:302.

Ketelaars, J. J. M. \& Tolkamp, B. J. 1992. Toward a new theory of feed intake regulation in ruminants 1 . Causes of differences in voluntary feed intake: critique of current views. Livest. Prod. Sci. 30., 269-296.

Kingsbury, L. R. 1965. Pasture quality in terms of soluble carbohydrates and volatile fatty acid production. Proc. Of the NZ Soc. of Anim. Prod. 25, 119-134.

KrysI, L. J. \& Hess, B. W. 1993. Influence of supplementation on behavior of grazing cattle. J. of Anim. Sci. 71:2546-2555.

Laca, E. A. \& Greenwood, G. B. 1987. Intake in grazing ruminants: A conceptual framework. Proc. Feed intake Symposium. Exp St. Oklahoma State Univ. 208-225. 
Laca, E. A. Ungar, E. D. \& Demment, M. W. 1994. Mechanism of handling time and intake rate of large mammalian grazer. Appl. Anim. Behav. Sci. 39:3.

Laredo, M. A. \& Minson, D. J. 1975. The voluntary intake and digestibility by sheep of leaf and stem fraction of Lolium perenne. J. Br. Grassl. Soc. 30:73-77.

Lechtemberg, V. L. Holt, D. A. \& Youngberg, H. W. 1971. Diurnal variation in non structural carbohydrates, in vitro digetibility and leaf to stem ratio of alfalfa. Agron. J. 63: 719-724.

Lechtemberg, V. L. Holt, D. A. \& Youngberg, H. W. 1972. Diurnal variation in non structural carbohydrates of festuca arundinacea (Schreb.), with or whithout $\mathrm{N}$ fertilizer. Agron. J. 64: 302-305.

León, R. J. C. Burkart, S. E. \& Movia, C. P. 1979. Relevamiento Fitosociológico del Pastizal del Norte de la Depresión del Salado. Serie Fitogeográfica No 17. La vegetación de la República Argentina, INTA. 90 pp.

Linnane, M. I. Brereton, A. J. \& Giller, P. S. 2001. Seasonal changes in circadian grazing patterns of Kerry cows (Bos Taurus) in semi-feral conditions in Killarney National Park, Co. Kerry, Ireland. Appl. Anim. Behav. Sci. 71: 277-292.

Mangan, J. L. Vetter, R. L. Jordan, D. J. \& Wright, P. C. 1976. The effect of condensed tannins of sainfoin (Onobrychis viciiafolia) in the release of soluble leaf protein into the food bolus of cattle. Proc. Nutr. Soc. 35:95.

Mangel, M. \& Clark, C. W. 1986. Towards a unified foraging theory. Ecology vol. 67 (5) 1127-1138.

Mayland, H. F. MacAdam, J. W. Shewmaker, G. E. \& Chatterton, N. J. 2003. The diurnal cycling of sugars in grasses impact strip-graze management plans. Pages 466-468 in Proc. Second Natl. Conf. Graz. Lands, December 7-10, 2003, Nashville, TN. Grazing Lands Conservation Initiative, Fort Worth, TX. 
Mayland, H. Gregorini, P. Mertens, D. R. Taylor, J. B. Burns, J. C. Fisher, D. S. Ciavarella, T. Smith, K. Shewmaker, G. \& Griggs. T. 2005. Diurnal changes in forage quality and their effects on animal preference, intake, and performance. p. 223 in Proc. 35th California Alfalfa and For. Symp., Visalia, CA.

Mattiauda, D. A. 2003. La Pastura como Insumo en la Formulación de Dietas. XXXI Jornadas Uruguayas de Buiatría. Paysandú. Uruguay.

McGilloway, D. A. Cushnaham, A. Laidlaw, A. S. Mayne, C. S. \& Kilpatrick, D. J. 2001. The relationship between the level of sward height reduction in a rotationally grazed sward and short term intake rates of dairy cows. Grass \& For. Sci. 54:116126.

Meijs, J. A. C. 1981. Herbage intake by grazing dairy cows. PhD Thesis. Wageningen Agric. Univ.

Meijs, J. A. C. Walters, R. J. \& King, A. 1982. Sward Methods. En J. D. Leaver ed. Herbage intake handbook. The British Grassland Soc. pp 11-36

Méndez, D. \& Davies, P. 2003. Calidad de forraje y bajas ganancias de peso otoñales. Ed INTA. Centro Regional Buenos Aires Norte, Argentina. 8p.

Mertens, D. R. 1994. Regulation of forage intake. In G.C. Fahey, M. Collins, D.R. Mertens, \& L.E. Moser (Eds.), Forage Quality, Evaluation and Utilization. (pp. 450493). Madison, WI: American soc. of Agronomy, Crop Sci. Soc. of America, Soil Sci. Soc. of America.

Metz, J. H. M. 1975. Time Patterns of Feeding and Rumination in Domestic Cattle. Mededelingen Landbouwhogeschool Wageningen. Nederland (75-12).

Miner, J. L. \& Baile, C. L. 1991. Advances in vegetation intake in grazing ruminants. Proc $2^{\text {nd }}$ grazing livestock nutrition conference. Agosto 1991. Stemboat springs. Colorado. USA. $150-156$. 
Monteith, J. L. \& Elston, J. 1983. Performance and productivity to foliage in the field, in the growth and functioning of leaves. Stanford University press. 229-251.

Newman, J. A. Parsons, A. J. \& Penning, P. D. 1994. A note on the behavioural strategies used by grazing animals to alter their intake rates. Grass and For. Sci., 49,502-505.

Newman, J. A. Parson, A. J. Thornley, J. H. M. Penning, P. D. \& Krebs, J. R. 1995 Optimal diet selection by a generalist grazing herbivore. Funct. Ecol. 9: 255268.

NRC. 1984. Nutrient Requirements of Beef Cattle (6th Ed.). Nat. Acad. Press, Washington,DC.

O`Connell, J. Giller, P. S. \& Meaney, W. 1989. A comparison of dairy cattle behavioural pattern at pasture \& during confinement. Ir. J. Agric. Food Res. 28:65-72.

Orr, R. J. Penning, P. D. Harvey, A. \& Champion, R. A. 1997. Diurnal patterns of intake rate by sheep grazing monocultures of rye grass or white clover. Appl. Anim. Behav. Sci. 53: 65-77.

Orr, R. J. Rutter, S. M. Penning, P. D. \& Rook, A. J. 2001. Matching grass supply to grazing patterns for dairy cows. Grass \& For. Sci. 56: 352-361.

Patterson, D. M. Mc Gilloway, D. A. Cuchnaham, A Mayne, C. S. \& Laidaw, A. S. 1998. Effect of duration of fasting period on short term intake rates of lactating dairy cows. An. Sci. 66, 299-305.

Pearson, C. J. \& Ison, R. L. 1994. Agronomía de los sistemas pastoriles. Ed Hemisferio sur. 157 pp. 
Penning, P. D. Rook, A. J. \& Orr, R. J. 1991a. Patterns of ingestive behaviour of sheep continuously stocked on monocultures of ryegrass or white clover. Appl. Anim. Behav. Sci. 31:237-250.

Penning, P. D. Parsons, A. J. Orr, R. J. \& Treacher, T. T. 1991b. Intake and behaviour response by sheep to change in sward characteristics under continuous stocking. Grass \& For Sci. 46; 15-28.

Penning, P. D. Parson, A. J. Newman, J. A. Orr, R. J. Harvey, A. 1993. The effect of group size on the grazing time in sheep. Appl. Anim. Behav. Sci. 37, 101-109

Pond, K. R. Ellis, W. C. \& Akin, E. E. 1984. Ingestive mastication and fragmentation of forages. J. Anim. Sci. 58:1567.

Poppi, D. P. Hughes, T. P. \& L'Huillier, P. J. 1987. Intake of pastures by grazing animals. En: Livestock feeding on pasture. NZ Soc. of Anim. Prod. Occ. Pub. No 10.

Provenza, F. D. 1996. Acquired aversions as the basis for varied diets of ruminants foraging on rangelands. J. Anim. Sci. 74:2010-2020.

Provenza, F. D. Villalba, C. D. Cheney, R \& Werner, S. J.. 1998. Self organization of foraging behaviour: from simplicity to complexity without goals. Nutrition Res. Rev. 11: $199-222$.

Radojevic, I. Simpson, R. J. St John, J. A. \& Humphreys, M. O. 1994. Chemical composition and in vitro digestibility of lines of Lollium perenne selected for high concentrations of water-soluble carbohidrate. Aust. J Agric. Res. 45: 901-912.

Realini, C. E. Hodgson, J. Morris, S. T. \& Purchas, R. W. 1999. Effect of sward surface heigth on herbage intake and performance of finishing beef cattle. NZ. J. Agric. Res. 42:55.

Reeves, M. Fulkerson, W. J. \& Kellaway, R. C. 1996. Forage quality of kikuyu (Pennisetum clandestinum): the effect of time of defoliation and nitrogen fertiliser 
application and in comparison with perennial ryegrass (Lollium perenne). Aust. J Agric. Res. 47: 1349:1359.

Ribeiro, J.M. de C.R. MacRae, J.C. \& Webster, A.J.F. 1981. An attempt to explain differences in the nutritive value of spring and autumn harvested dried grass. Proceedings of the Nut. Soc., 40, 12A.

Robson, M. J. Parsons, A. J. \& Williams, T. E. 1989. Herbage production: grasses and legumes. In: Holmes, W. (Ed.), Grass, its Production and Utilization, 2nd Edition. British Grassland Soc., Blackwell, Oxford, pp. 7-88.

Rook, A. J. \& Huckle, C. A. 1996. Sources of variation in grazing behaviour in dairy cows. J. Agr. Sci. Cambridge, 126. 227-233

Rook, A. J. 2000. Grass: Its Production \& utilization. Principles of foraging \& grazing behaviour. Cap. 9 pp. 229-246.

Rook, A. J. 2004. Herbage intake handbook. Chapter 7: Statistical considerations in the design of herbage intake studies. Editado po: P.D.PENNING. Publicado por: The British Grassland Soc.

Rook, A. J. \& Huckle, C. A. 1997. Activity bout criteria for grazing dairy cows. Appl. Anim. Behav. Sci. 54:89.

Rook, A. J. Huckle, C. A. \& Penning, P. D. 1994. Effect of sward height \& concentrate supplementation on the ingestive behaviour of spring calving dairy cows grazing grass clover swards. Appl. Anim. Behav. Sci. 40: 101-112.

Sinclair, A. R. E. 1977. The African buffalo: a study of resource limitation of populations. University of Chicago Press. Chicago.

Sicher, R. C. \& Kremer, D. F. 1984. Changes of sucrose-phosfate synthase activity in barley primary leaves during dark/light transition. Plant Physiol. 76: 910-912 
Smit, H. J. Taweel, H. Z. Tas, B. M. Tamminga, S. \& Elgersma, A. 2005. Comparison of techniques for estimating herbage intake of grazing dairy cows. J. Dairy Sci. 88:1827-1836.

Taweel, H. Z. 2004. Perennial ryegrass for dairy cows: Grazing behaviour, intake rumen function and performance. Ph.D. Diss., Wageningen Univ., Wagen. The Netherlands.

Taweel, H. Z. Tas, B. M. Dijkstra, J. \& Tamminga, S. 2005. Intake regulation and grazing behavior of dairy cows under continuous stoking. J. Dairy Sci. 87:3417.

Thornley, J. H. M. Parsons, A. J. Newman, J. \& Penning, P. D. 1994. A costbenefit model of grazing intake and diet selection in a two-species temperate grassland sward. Func. Ecol. 8, 5-16.

Tilley, J. M. \& Terry, R. A. 1963. A two-stage technique for the in vitro digestion of forage crops. J. Brit. Grassl. Soc. 18:104-111.

Trevaskis, L. M. Fulkerson, W. J. \& Nandra, K. S. 2004. Effect of time of feeding carbohydrate supplements and pasture on production of dairy cows. Livest. Prod. Sci. 85:275-285.

Ulyatt, M. J. 1973. The feeding value of herbage. In (Butter, G.W. and Bailey, R.W.; eds.). Chemistry and biochemistry of herbage. London, Academy press. Vol. 3, pp 131-178.

Van Soest, P. J. 1982. Nutritional Ecology of the Ruminants. O \& B Books, Corvallis, OR.

Van Soest, P. J. Robertson, J. B. \& Lewis, B. A. 1991. Methods of dietary fiber, neutral detergent fiber, and non starch polysaccharides in relation to animal nutrition. J. Dairy Sci. 74:3583-3597. 
Van Vuuren, A. M. 1993. Digestion and nitrogen metabolism of grass in dairy cows. Ph.D. Diss., Wageningen Univ., Wagen. The Netherlands.

Van Vuuren, A. M. Van der koelen, C. J. \& Vroons-de bruin, J. 1986. Influence of level and composition of concentrate supplements on rumen fermentation patterns of grazing dairy cows. Neth. J. Agric. Sci. 34: 457-467.

Wade, M. H. Eirin, M. A. \& Gregorini, P. 2006 The effect of fasting on the feeding station behaviour of grazing beef heifers. J. Anim. Sci. 84 (Suppl 2):17. (Abstr.)

Waite, R. \& Boyd, J. 1953. The water-soluble carbohydrates of grasses. I. Changes occurring during the normal life cycle. J. of the Sci. of Food and Agric. 4, 197-204.

White, L. 1973. Carbohidrate reserves of grasses: a review. J. Range Man. 26: 1318.

Wilman, D. 1965. The effect of nitrogenous fertilizer on the rate of growth of italian ryegrass. J. Br. Grassl. Soc. 20: 248-254.

Winchester, C. F. \& Morris, M. J. 1956. Water intake rates of cattle. J. Anim. Sci. $15: 722$

Wulfes, R. Nyman, P. \& Kornher, A. 1999. Modeling non structural carbohydrates in forage grasses with weather data. Agric. Syst. 61: 1-16.

Yemm, E. C. \& Willis, A. J. 1954. Estimation of carbohydrates in plant extracts by anthrone. Biochem. J. 57:508-514.

Youngberg, H. W. Holt, D. A. \& Lechtemberg, V. L. 1972. Diurnal variation in nitrogenous constituents of alfalfa (Medicago sativa L.). Agron. J. 64:288-291. 
